Review

\title{
Phase change and crystallization behavior of water in biological systems and innovative freezing processes and methods for evaluating crystallization
}

\author{
Ehsan Parandi ${ }^{1} \cdot$ Milad Pero $^{1} \cdot$ Hossein Kiani ${ }^{1}$ \\ Received: 20 November 2021 / Accepted: 16 December 2021 \\ Published online: 01 February 2022 \\ (c) The Author(s) 2022 OPEN
}

\begin{abstract}
The phase change of water occurs in biological samples during freezing and introduces significant changes to the processed materials. The phase change phenomenon includes complex processes at the macro and micro levels. At molecular levels, water undergoes a rate-limiting nucleation stage to form templates for the next step called crystal growth. The rate and interaction of these two stages play an essential role in the characteristics of the process and the products. Technically, crystal size distribution and its control through processing parameters are linked to the properties of products. Thus, understanding the interactions between water phase change steps, evaluating the effects of crystallization and ice crystals features, and employing novel techniques to control and monitor nucleation and crystal growth stages is essential for improved frozen products quality. Finding the moisture behavior information with direct and indirect measurements can describe crystals in multi-perspectives, providing practical knowledge on the mechanisms of the freezing process. Moreover, innovative novel freezing technologies improve the crystallization process during the freezing of foods. This review focuses on an overview of the water phase change and crystallization process. Specific emphasis was placed on modeling approaches, the measuring methods, and novel accelerating and suppression of nucleation and ice crystals growth.
\end{abstract}

Keywords Freezing $\cdot$ Food $\cdot$ Ice crystal $\cdot$ Phase change $\cdot$ Crystallization

\section{List of symbols}

$\Delta G \quad$ Overall excess free energy, J

$\Delta G_{c} \quad$ Critical free energy for nucleation, J

$\Delta \mathrm{G}_{\mathrm{c} \text {, het }}$ Nucleation energy of heterogeneous nucleation, J

$\Delta G_{s} \quad$ Surface excess free energy, J

$\Delta G_{v} \quad$ Volume excess free energy, J

$\Delta G_{v} \quad$ Free energy change of the transformation per unit volume, $\mathrm{J} \mathrm{m}^{-3}$

$\Delta \mathrm{T}_{\mathrm{s}} \quad$ Supercooling, ${ }^{\circ} \mathrm{C}$

A Surface area, $\mathrm{m}^{2}$

$A_{1} \quad$ Preexponential term of nucleation rate equation, $\mathrm{s}^{-1} \mathrm{~m}^{-3}$

$a_{\text {for }} \quad$ The volumetric surface of foreign particles, $\mathrm{m}^{2} \mathrm{~m}^{-3}$

$B$ Rate of nucleation, nuclei per unit volume per unit time

Hossein Kiani, hokiani@ut.ac.ir | ${ }^{1}$ Department of Food Science \& Technology, Faculty of Agricultural Engineering and Technology, University of Tehran, Karaj, Iran. 
$B_{\text {het }} \quad$ Rate of heterogeneous nucleation, nuclei per unit volume per unit time

$B_{\text {hom }} \quad$ Rate of homogeneous nucleation, nuclei per unit volume per unit time

$B_{s} \quad$ Rate of surface nucleation, nuclei per unit area of crystal surface per unit time

C Actual concentration, $\mathrm{mol} \mathrm{L}^{-1}$

$\mathrm{C}_{0} \quad$ The concentration of nucleation sites, $\mathrm{m}^{-3}$

$\mathrm{C}_{1} \quad$ Constant

$\mathrm{C}_{2} \quad$ Constant

$\mathrm{C}_{\mathrm{ad}} \quad$ Concentration on the surface, $\mathrm{mol} \mathrm{kg}^{-1}$

$C_{C} \quad$ The molar density of the solid, $\mathrm{m}^{3} \mathrm{~mol}^{-1}$

$\mathrm{D}_{\mathrm{AB}} \quad$ Diffusivity, $\mathrm{m}^{2} \mathrm{~s}^{-1}$

$\mathrm{d}_{\mathrm{m}} \quad$ Molecular diameter, $\mathrm{m}$

$D_{\text {surf }} \quad$ The surface-diffusion coefficient of units moving on the foreign surface, $\mathrm{m}^{2} \mathrm{~s}^{-1}$

$\mathrm{dm} / \mathrm{dt} \quad$ Crystal growth rate, $\mathrm{kg} \mathrm{s}^{-1}$

$\mathrm{dq} / \mathrm{dt} \quad$ Rate of heat transfer, $\mathrm{J} \mathrm{s}^{-1}$

$f^{*} \quad$ Natural frequency, $\mathrm{s}^{-1}$

g Constant

$\mathrm{G} \quad$ Rate of crystal growth, $\mathrm{kg} \mathrm{s}^{-1}$

$\mathrm{h} \quad$ Film heat transfer coefficient, $\mathrm{W} \mathrm{m}^{-2}{ }^{\circ} \mathrm{C}^{-1}$

$\mathrm{He}_{\mathrm{ad}}$ Adsorption constant

$k \quad$ Boltzmann constant

$\mathrm{K}_{1} \quad$ Thermal conductivity, $\mathrm{W} \mathrm{m}^{-1}{ }^{\circ} \mathrm{C}^{-1}$

$\mathrm{K}_{\mathrm{G}} \quad$ Overall crystal growth coefficients

n Constant

$\mathrm{n}_{0} \quad$ Concentration of monomers in the supersaturated solution

$\mathrm{N}_{\mathrm{A}} \quad$ Avogadro's number $\left(\mathrm{N}_{\mathrm{A}}=6.023 \times 10^{23} \mathrm{~mol}^{-1}\right)$

$\mathrm{n}_{\mathrm{c}} \quad$ Number of stable nuclei

$r \quad$ Particle radius, $m$

$r_{c} \quad$ Critical nucleus radius, $m$

$\mathrm{s} \quad$ Initial freezing front position, $\mathrm{m}$

$S \quad$ Supersaturation ratio

$\mathrm{S}_{\text {met, s }} \quad$ Relative supersaturation

$\mathrm{T}^{*} \quad$ Melting point, ${ }^{\circ} \mathrm{C}$

$\mathrm{T} \quad$ Temperature, ${ }^{\circ} \mathrm{C}$

$\mathrm{t} \quad$ Time, $\mathrm{s}$

$\mathrm{T}_{\mathrm{f}} \quad$ Initial freezing temperature, ${ }^{\circ} \mathrm{C}$

$\mathrm{T}_{\mathrm{i}} \quad$ Interfacial temperature, ${ }^{\circ} \mathrm{C}$

$V_{m} \quad$ Volume of a unit, $\mathrm{m}^{3}$

W Work, J

$W_{s} \quad$ Work required to form a surface, $J$

$W_{v} \quad$ Work required to form the bulk of a particle, $J$

$\mathrm{z} \quad$ Zeldovich or Imbalance factor

$x \quad$ Length, $m$

$\beta \quad$ Constant

$\sigma \quad$ Surface energy of the particle per unit area, $\mathrm{J} \mathrm{m}^{2}$

$v \quad$ The number of molecules or ions

$\theta \quad$ The wetting or contact angle, deg

$\mathrm{Y}_{\mathrm{CL}} \quad$ The surface tension, $\mathrm{N} \mathrm{m}^{-1}$ 


\section{Introduction}

Freezing is among the most critical and influential unit operations [1] for the preservation of perishable foods to prevent microbial growth and reduce biochemical reactions [2], besides preserving organoleptic properties [3]. The freezing process of food materials includes three stages: precooling, phase change, and tempering [4]. Crystallization is defined as a critical phenomenon which is occurred in the second stage of freezing, consisting of the formation of ice crystals and subsequent crystal growth [2]. In the freezing of food materials, the creation of large ice crystals causes some problems, such as weakening the physical structure in porcine longissimus muscles [5]. In contrast, the generation of small and homogeneously distributed ice crystals in the intracellular region causes to bring about high-quality foods [1] and leads to fewer damages to the food structure. Thus, understanding the crystallization phenomenon, control of nucleation and ice crystal growth during the freezing process and in frozen foods, and assessing methods to evaluate crystallization is crucial.

Crystallization is known as the diverse phenomenon that leads to the creation of crystalline lattice structures, comprising two integrated steps, including nucleation and ice crystal growth [2]. Supercooling and supersaturating are the most important driving forces to crystallization. High supercooling degrees make small ice crystals, which cause fewer deterioration effects to the food structures [6]. The ice crystal size is mostly dependent upon nucleation temperature (the temperature that the first ice nucleus will appear). The efficiency of the freezing process is directly related to the size, morphology and distribution of ice crystals [7]. Theoretical modelling and experimental evaluation can be employed to better understand water crystallization, leading to handling and improving the freezing process. Some theoretical modelings, including thermodynamic, heat transfer, and mass transfer principles, describe the complicated process of nucleation and ice crystal growth [4]. Furthermore, there are many types of experimental analyzing methods to visualize the crystallization phenomenon and its effects on frozen foods, including light microscopy, Cryo-microscopy, scanning electron microscopy (SEM), environmental scanning electron microscopy (ESEM), transmission electron microscopy (TEM), atomic force microscopy (AFM), magnetic resonance imaging (MRI), and nuclear magnetic resonance (NMR) have been employed [2].

Traditional freezing methods (slow freezing methods), including air blast freezing, immersion freezing, cryogenic freezing, direct-contact freezing $[8,9]$ have some defects such as heterogonous distribution, size variation, also morphological diversity of ice crystals, in which cause drip loss in plant tissue, squeezing effect in meat tissue, and other drawbacks in food materials. Therefore, employing novel freezing techniques (rapid freezing methods) for reducing damages of freezing is essential [8]. Controlling of ice crystals nucleation and subsequent ice crystals growth has been evaluated by ultrasound-assisted freezing (UAF) [10], electrically disturbed freezing (EF) [11], magnetically disturbed freezing (MF) [12], microwave-assisted freezing (MAF) [13], radiofrequency freezing (RF) [14], high-pressure freezing (HPF) [15], osmo-dehydro-freezing (ODF) [16], ice nucleating proteins (INPs) [17], antifreeze proteins (AFPs) and antifreeze glycoproteins (AFGPs) [18]. Compared with conventional freezing methods, several benefits are reported by employing novel freezing approaches, including maintaining nutritional value [5, 12], better flavor and taste [19], retarding the browning index [20], enzymes inactivations [21], reducing the drip loss [13, 22, 23], keeping water holding capacity $[24,25]$, retaining better texture $[13,26]$, more stable colour parameters $[13,15,22]$, etc.

In this review, we first summarized the ice crystallization phenomenon and its importance. Modeling approaches are then introduced. Finally, evaluation methods of ice crystals are discussed, followed by an overview of novel freezing methods to trigger and suppress ice crystallization.

\section{Ice crystallization phenomenon}

The freezing process has three stages [4], including the precooling or chilling stage (removing sensible heat), phase change stage (the removal of latent heat), and tempering stage (cooling to the storage temperature of food products, and finally cessation of growth). Due to the supercooling (reducing the temperature of food samples below their freezing point without solidification) [19] and supersaturation (surpassing the concentration of a solute from its specified equilibrium solubility), the substances can be precipitated, which is called crystallization. Crystallization occurs in the second step of the freezing process. As stated before, the crystallization phenomenon includes 
two main steps, i.e., nucleation and ice crystal growth. The crystal characteristics, including size, morphology, and distribution, are determined by the interaction between nucleation and crystal growth $[2,4]$.

During nucleation, thermo-dynamically stable aggregates are produced by associating a large amount of molecules, called parent or critical nuclei. Nucleation is a stochastic process divided into primary nucleation (the formation of ice crystals in the free-crystals solutions) and secondary nucleation (creating ice crystals in the solutions with pre-created ice crystals). There are two kinds of primary nucleation: homogenous (without foreign particles) and heterogeneous (if foreign particles are presented). A huge supercooling degree is desired to produce homogenous ice crystals in the primary nucleation step. In real food samples, due to the lower supercooling degrees, heterogeneous nucleation is easier than homogenous nucleation [27]. Secondary nucleation is occurred by the fracture of parent ice crystals $[2,4,27]$.

The second step of crystallization is ice crystal growth, which is either immediately followed by nucleation or can be occurred at the same time. Nuclei, which are produced in the nucleation step, serve as platforms for ice crystal growth. The diffusion of particles to the surface of the parent nuclei causes to the growth of ice crystals $[2,4,27,28]$. Both mass transfer and heat transfer are the main influential factors for ice crystal growth [2]. The ice crystal growth step can affect the size and distribution of ice crystals [7]. Nucleation and subsequent ice crystal growth are multi-parameter phenomena affected by chemical parameters like small molecules impurities, crosslinkers, $\mathrm{pH}$, etc., physical parameters such as temperature, pressure, viscosity, time, nucleation, dielectric properties, as well as biological factors like purity, homogeneity, aggregation, inhibitors, proteolysis [27, 29, 30].

\section{Modeling approaches}

The crystallization process consists of two stages, namely nucleation and crystal growth. The nucleation stage is defined as the formation of new crystals, taking place in two forms of primary nucleation and secondary nucleation. In primary nucleation, new crystals are formed in a crystal-free solution, but in secondary nucleation, the new crystals are formed in the presence of formerly created crystals. If the nuclei are formed in a solution free of foreign particles and crystals, it will be called homogeneous primary nucleation, but if they are formed in the presence of foreign particles, then it will be defined as heterogeneous primary nucleation [4].

There have been various mathematical models for describing the crystallization phenomena. Therefore, in this section, the mathematical modeling of the crystallization will be discussed in detail.

\subsection{Primary nucleation}

The work needed for the formation of the nucleus is the sum of the work required for the creation of the surface of the crystal, $\mathrm{W}_{\mathrm{s}^{\prime}}$ and the work needed for the creation of the volume of the nucleus, $\mathrm{W}_{\mathrm{v}}$.

$$
W=W_{s}+W_{v}
$$

The surface term is an endothermic process. Therefore, a positive quantity that permits the molecular aggregate to consume some of the nucleation energy or to dissolve into the continuous medium. The volumetric term is an exothermic and therefore a negative quantity, which reduces Gibbs free energy [31]. In fact, the surface term is against the nucleation, but the volumetric term is in favor of the nucleation [32]. According to these explanations, the Eq. 1 can be rewritten based on Gibbs free energy [33]:

$$
\Delta G=\Delta G_{s}+\Delta G_{V}
$$

In the case of a spherical particle:

$$
\Delta G=4 \pi r^{2} \sigma+\frac{4}{3} \pi r^{3} \Delta G_{v}
$$

where $\Delta \mathrm{G}$ is the excess free energy difference between the solute in a small solid particle and solute in the solution, $\Delta \mathrm{G}_{\mathrm{v}}$ is the excess free energy of the volume, $\Delta G_{s}$ is the excess free energy of the surface, $\Delta G_{v}$ which is a negative quantity is the changes in free energy of the transformation per unit volume, $\sigma$ is the surface energy of the particle per unit area. The $\Delta G$ has a maximum value in a specific value for $r$, which is called the critical nucleus radius $\left(r_{c}\right)$. The corresponding 
$\Delta G$ is called the critical free energy of the nucleation $\left(\Delta G_{c}\right)$. For a cluster with a radius lower than the $r_{c^{\prime}}$ there is a need of energy for the attaching molecule to reach $\Delta G_{c}$. But, if the cluster has a radius higher than the $r_{C^{\prime}}$ the $\Delta G$ of the attaching molecule will be lower than the $\Delta G_{c}$. In this case, this crystal is stable and will grow.

In the crystallization system, the nuclei with radii larger than the $r_{c}$ have the opportunity to develop at the macroscopic level. Therefore, the term nucleation rate $(B)$ is defined as the number of the created nucleus per unit time per unit volume or area [34]. The proposed model by Volmer and Weber [35], which was modified based on thermodynamic considerations and Gibbs free energy $[33,34]$ is the most used formula for describing the nucleation rate (B):

$$
B=A \exp \left(\frac{-\Delta G_{c}}{k T}\right)
$$

where, the term $A_{1}$ is:

$$
A_{1}=z f^{*} C_{0}
$$

where $T$ is the temperature, $k$ is the Boltzmann constant, $f^{*}$ is the frequency of monomer attachment to the nucleus, $C_{0}$ is the concentration of nucleation sites and $z$ is the Zeldovich or imbalance factor. The factors that influence the $f^{*}$ are the temperature, surface area of particles, concentration and the diffusion coefficient of the molecules. The Zeldovich factor relates the number of critical nuclei in the equilibrium distribution to the number in the steady-state distribution. It is a function of surface area, surface tension, concentration, temperature and Avogadro number.

For any nucleation process, Eq. 4 can be used with modifications [33, 34, 36-38]. Based on the thermodynamic properties of the system and estimating the main terms of the equation, the Eq. 4 can be rewritten for homogeneous and heterogeneous systems as Eqs. 6 and 7, respectively [36]:

$$
\begin{gathered}
B_{\text {hom }}=\frac{3}{2} D_{A B}\left(C N_{A}\right)^{\frac{7}{3}} \sqrt{\frac{\gamma_{C L}}{k T}} \frac{1}{C_{C} N_{A}} \exp \left[-\frac{16}{3} \pi\left(\frac{\gamma_{C L}}{k T}\right)^{3}\left(\frac{1}{C_{C} N_{A}}\right)^{2} \frac{1}{(v \ln S)^{2}}\right] \\
B_{h e t}=\frac{1}{2 \pi} a_{f o r} d_{m} H e_{a d}\left(C N_{A}\right)^{\frac{7}{3}} \sqrt{\frac{f \gamma_{C L}}{k T}} V_{m}\left(\frac{(\sin \theta) D_{\text {surf }}}{r_{c}} H e_{a d} d_{m}^{\frac{3}{2}}\left(C N_{A}\right)^{\frac{1}{6}}+3 \pi D_{A B}(1-\cos \theta)\right) \exp \left[-f\left(\frac{16}{3}\right) \pi \frac{\gamma_{C L}}{k T} r_{c}^{2} \frac{1}{(v \ln S)^{2}}\right]
\end{gathered}
$$

where, $D_{A B}$ is the diffusivity, $N_{A}$ is the Avogadro number, $V_{C L}$ is the surface tension, $C$ is the actual concentration, $C_{C}$ is the molar density of the solid, $v$ is the number of ions or molecules, $f$ is the geometric correction factor for homogeneous nucleation, $S$ is the supersaturation ratio, $\theta$ is the wetting or contact angle, $d_{m}$ is the molecular diameter, $a_{f o r}$ is the volumetric surface of foreign particles, $\mathrm{V}_{m}$ is the volume of a unit, $\mathrm{He}_{\mathrm{ad}}$ is the adsorption constant, $\mathrm{D}_{\text {surf }}$ is the surface-diffusion coefficient of units moving on the foreign surface.

The nucleation of ice can also be described in a similar way as Eq. 4 based on the degree of super-cooling in the system $[39,40]$ :

$$
B=C_{1} \operatorname{Texp}\left(\frac{-C_{2} T_{f}^{2}}{T^{2} \Delta T_{s}}\right)
$$

$T$ is the temperature of the system, $C_{1}$ and $C_{2}$ are the coefficients, which is dependent on the type of the product, $T_{f}$ is the initial freezing temperature and $\Delta \mathrm{T}_{s}$ is the super-cooling.

As seen from the presented equations, the rate of nucleation for both the homogeneous and heterogeneous system is dependent on the super-cooling or supersaturation, temperature, diffusivity, the actual concentration and the equilibrium concentration, and molar density. Therefore, the driving force of the nucleation is super-cooling or supersaturation, which is a function of temperature or concentration. The rate of nucleation in the case of heterogeneous systems is much higher than that of homogeneous systems. Therefore, its rate is also dependent on the additional parameters such as the volumetric surface $\left(\mathrm{a}_{\mathrm{for}}\right)$ of the foreign particles in the nucleation system, the contact angle $(\theta)$, the adsorption constant $\left(\mathrm{He}_{\mathrm{ad}}\right)$, and the 
surface diffusion coefficient $\left(D_{\text {surf }}\right)$. The volumetric surface of the foreign particles is more important than their number, and it is considered a critical parameter for heterogeneous nucleation.

\subsection{Secondary nucleation}

As stated earlier, secondary nucleation takes place in a system containing already created crystals; therefore, the present crystals act as a catalyzer for the nucleation process. In this case, the nucleation rate is much higher than the primary nucleation and can occur at a lower supersaturation degree.

Secondary nucleation can take place similar to the primary nucleation as follow [36, 41, 42]:

$$
B_{s}=\frac{D_{A B}}{d_{m}^{4}} \exp \left(\pi \frac{-\gamma_{C L}^{2} d_{m}^{4}}{(K T)^{2} v \ln S_{\text {met.s }}}\right)
$$

where, $B_{s}$ is the rate of the surface nucleation, $\Delta G_{m a x, s}$ is the nucleation energy, $D_{A B}$ is the diffusivity, and $S_{\text {met, } s}$ is the relative supersaturation.

\subsection{Crystal growth}

For the crystallization phenomenon in which the main driving force is temperature reduction, the most important factor is the rate of heat transfer from the crystal surface to the surrounding medium [33]. When the molecules of the melt are deposited on the surface of the crystal, due to the liberation of the latent heat of phase change, the surface of the crystal will have a higher temperature than the surrounding medium. Therefore, a temperature gradient is created between the surface of the crystal and the super-cooled melt. In this case, the Newton law of cooling is used to describe the heat transfer [33]:

$$
\frac{d q}{d t}=h A\left(T_{i}-T\right)
$$

In the frozen part of the material undergoing the freezing process, the dominant mechanism of heat transfer is conduction heat transfer which is described by Fourier's first law of conduction; therefore, the rate of heat conduction in the x-direction is:

$$
q_{x}=-K_{1} A \frac{d T}{d x}
$$

The rate of crystal growth, $\mathrm{dm} / \mathrm{dt}$ (mass per unit time) is:

$$
\frac{d m}{d t}=K_{G} A\left(T^{*}-T\right)^{g}
$$

where $A$ is the surface area of the growing crystal, $h$ is the convective heat transfer coefficient, $T_{i}$ is the interfacial temperature, $T$ is the temperature of the super-cooled material, $m$ is the mass of solute deposited on the surface of the crystal in time, $T^{*}$ is the melting point, $\mathrm{K}_{1}$ is the thermal conductivity, $\mathrm{K}_{\mathrm{G}}$ is the overall crystal growth coefficients, $\mathrm{x}$ is length $(\mathrm{m})$ and $\mathrm{T}$ is temperature. The $\mathrm{g}$ is a value between $1.5-2.5$, which is referred to the order of the overall crystal growth.

Similar mathematical models can also be used for describing the rate of crystal growth in the freezing process of foodstuff. There are experimental models for calculating the rate of water crystallization. Following is an experimental equation similar to that of Eq. 12 for calculating the rate of water crystallization [39]:

$$
G=\beta\left(\Delta T_{s}\right)^{n}
$$

where $\beta$ and $\mathrm{n}$ are constants obtained from experimental data and $\Delta \mathrm{T}_{\mathrm{s}}$ is super-cooling.

\section{Methods for evaluation of crystallization}

The size, distribution and morphology of ice crystals have important effects on the quality of the frozen product [2]. The freezing rate is the most important frozen condition which influences these properties. The formation of large ice crystals and their uneven distribution may rupture the cellular structure and therefore cause the loss of texture and nutrients 
giving poor sensory properties to the final product. Ice crystals with finer size and even distribution are generated at a high freezing rate, while at lower freezing rates, large and uneven ice crystals are formed in the food tissue [43]. In Table 1, the advantages and drawbacks of various methods for measuring ice crystallization have been presented.

In this regard, several methods have been developed to analyze the size, morphology and distribution of ice crystals. In this section, these methods will be described.

\subsection{Microscopy}

There are three types of microscopic techniques that can be applied to study the effect of ice crystal formation on the quality of frozen products: destructive methods, direct methods and indirect methods. The first two methods are carried out by optical microscopy and the third one is carried out by electronic microscopy [49].

\subsubsection{Optical microscopy}

Optical microscopy is one of the most common methods for characterizing frozen foods. It gives information about the characteristics and size distribution of ice crystals as well as structural changes of the crystals during the storage of frozen foods. Compared to other methods, this technique is inexpensive and does not have a complicated sample preparation. As stated earlier, this technique is classified into destructive and direct methods. In destructive optical microscopy, the sample is mixed with a specific medium to disperse the ice crystals and dissolve other phases [50]. The advantages of this technique are the short time of the experiment and easy collection of data about the ice crystals distribution. However, due to the sample destruction, one cannot obtain data regarding the relative position of ice crystals and their volume fraction. In a study conducted by Donhowe et al. [50], the morphology and size distribution of ice crystals in the frozen dessert was analyzed by optical microscopy. In the preparation stage, they placed an ice cream sample on the slide and a drop of ethyl acetate was added to the sample to destroy the air cells present in the sample in order to increase the clarity and precision of ice crystal image analysis. Then, the obtained micrographs of ice crystals were analyzed for their morphology and size distribution.

In direct optical microscopy, the original texture of the sample is preserved. Photonic microscopy with episcopic coaxial lighting is used for this purpose. The principle of this method is based on the reflected light from the surface of the material [51]. This method was first developed by Arnaud et al. [50] for studying the polar ices, and its first application in food science was carried out by Faydi et al. [51] who studied the structure of the ice crystals the ice creams. In a recent application, Fiol et al. (2017) investigated the distribution and microstructure of the ice crystal in ice cream. A micrograph obtained by episcopic coaxial lighting from an ice cream sample can be seen in Fig. 1. The retention of the product's original texture, easy handling and low running costs are the main advantages of the optical microscopy with the episcopic coaxial lighting method. The main limitation of the coaxial episcopy is the small observation area.

In some cases, an optical microscope is equipped with a cryogenic system that comprises a cooling chamber containing a cooling stage for placing the specimen. A cryogenic material such as liquid nitrogen is coupled with the cooling chamber. This method is usually applied to monitor the sample's nucleation and ice crystal formation. Takako et al. [52] developed a special cry-microscope to monitor the intracellular ice crystal formation in the epidermal tissues of strawberry geranium. They used an inverted microscope equipped with a cryogenic system and a high speed camera (Fig. 2). Cheng Dai et al. (2016) used a cryo-microscopic technology for studying the ultrasound-assisted nucleation in the freeze drying process of carrot [53].

\subsubsection{Electron microscopy}

The principle of imaging by electron microscopy (EM) is similar to optical microscopy. The difference lies in the source of illumination, which is a beam of accelerated electrons in the case of EM. Due to the fact that the wavelength of electrons is much shorter than the visible light photons, the EM poses a higher resolution capacity than that of optical microscopy. Therefore, it can be used for imaging of smaller objects. The resolution of light microscopy is about $200 \mathrm{~nm}$, while for electron microscopy, this value is $5 \mathrm{~nm}$ [2]. This technique has been widely used to analyze the microstructure of food products. There are two types of EM: scanning electron microscopy (SEM) and transmission electron microscopy (TEM).

4.1.2.1 SEM SEM system has three main parts: an imaging system, an electron beam system and a vacuum system. Due to its high magnification ranging from 10 to 300,000 times, SEM can provide more detailed information than optical 


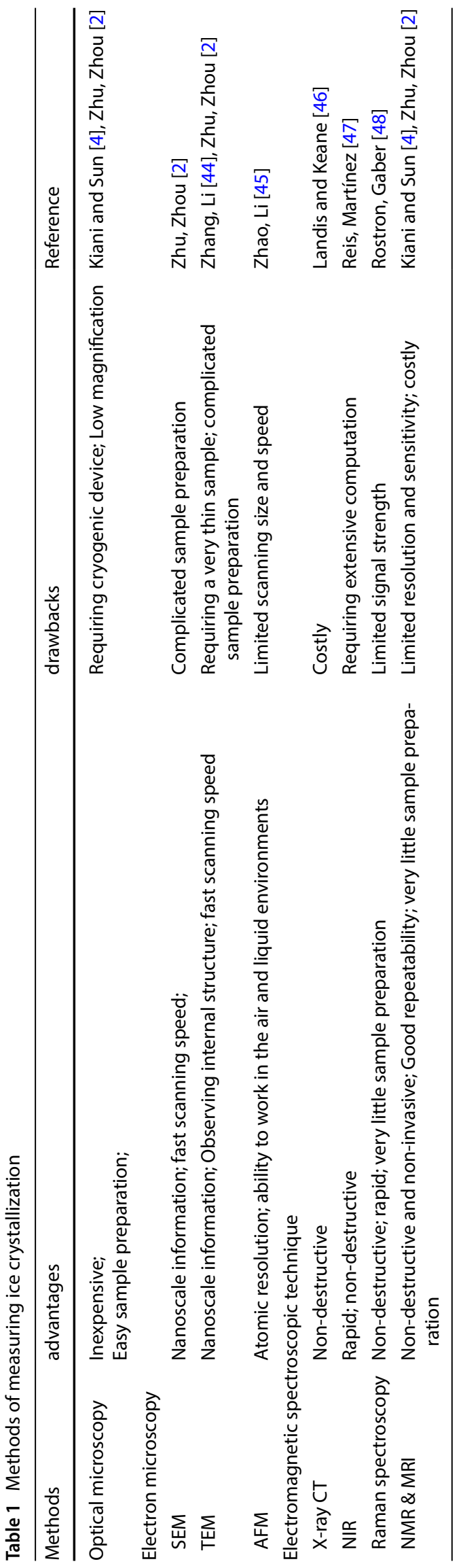


Fig. 1 The structure of ice cream was obtained by the direct microscopy [49]
Fig. 2 The cryo-microscope was developed by Takako et al. (2016) to monitor intracellular ice crystal formation [52]
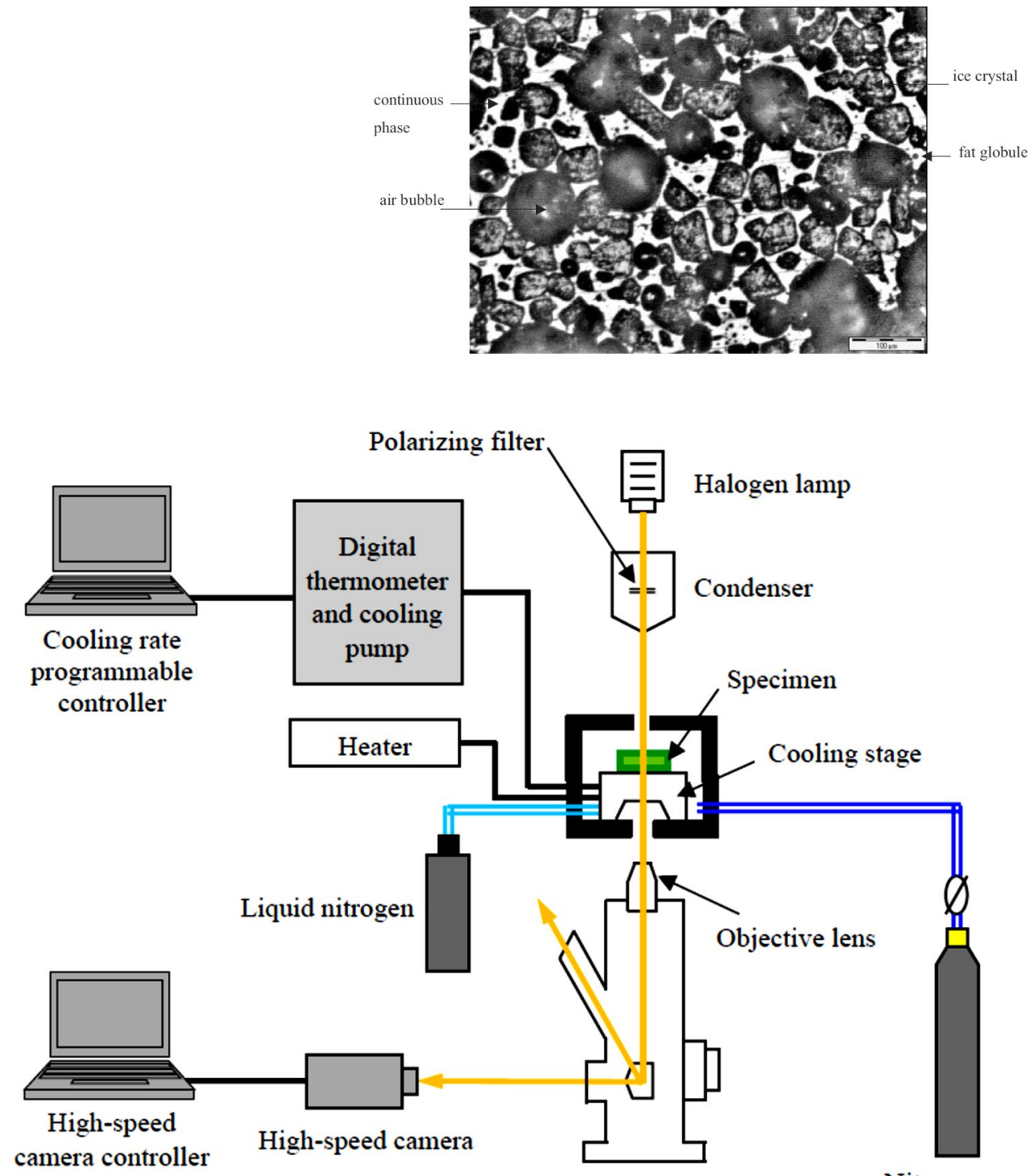

Inverted microscope

Nitrogen gas

microscopy [2]. In this system, a beam of energetic electrons interacts with the surface of the specimen and then they are reflected and produce a 3D image from the surface of the sample [54]. Therefore, there is no need for a strict sample preparation to reach a desired thickness. Operation under vacuum prevents the scattering of the incident electron beam or produced electrons [55]. In the conventional high vacuum SEM, in order to obtain a more realistic image, the surface of the sample is usually coated with a conductive material such as gold [55]. This conductive layer prevents thermal damage or charging of the sample by the electron beam [56]. In the low vacuum SEM, the observation of non-conductive material can be supported, but it has not been used for the analysis of frozen foods yet.

In addition to the conventional SEM system, two SEM techniques are cryo-SEM and environmental scanning electron microscopy (ESEM) for observing the ice crystals. The conventional SEM is not suitable for studying material with high water content because SEM operates under vacuum and dehydration of sample may occur under this operating condition. In contrast to conventional SEM, ESEM allows non-conductive samples with high water content to be imaged in their native state without sample preparation [57]. However, the disadvantage of this technique is its low resolution [55]. Cryo-SEM has a higher resolution than the ESEM and therefore, more details are obtained from the sample. However, it is more expensive and time-consuming and therefore, for the large number of samples, ESEM is more suitable [2]. Due to the possession of a chilling system, cryo-SEM can be used for direct imaging of frozen samples. Moreover, unfrozen samples can be placed in the microscope and the freezing process can take place during the imaging. Jha et al. (2020) studied the effect of microwave-assisted freezing on the apple and potato quality properties. The SEM graphs of apple sample 
are seen in Fig. 3. In this image, the bright regions are solidified solutes of the cell sap, cell walls and the cytoplasmic membrane. The dark spaces are ice crystals and some of the dark regions are related to the air space between the cells.

4.1.2.2 TEM In this electron microscopic technique, a beam of electrons is transmitted into the specimen. The scattered and un-scattered electrons passed through the specimen are collected and magnified producing a two-dimensional (2D) image of the sample's microstructure is obtained [54]. TEM is usually used for investigating the effect of ice crystals on the structure of frozen food matrices instead of the ice crystals themselves. Sample preparation in TEM is more complicated than in SEM. In most cases, the sample is cut into a very thin layer in the range of $40-100 \mathrm{~nm}$ and is stained prior to analysis. Since the electron beam is easily scattered, therefore, the thinness of the sample in TEM analysis is an important criterion. Lili et al., (2013) used TEM for investigating the effects of freezing on the microstructure of soybean [58]. By this technique, they found that the freezing process induces the coalescence of oil bodies and protein storage vacuoles in soybean seeds. In a study conducted by Phothiset and Charoenrein (2014), the microstructure of papaya subjected to freeze-thaw cycles was analyzed [59]. They observed that due to the freeze-thaw cycle, the cell wall materials in the middle lamella are lost as indicated by a decrease in the stain of the center zone of the cell wall.

4.1.2.3 Atomic force microscopy (AFM) AFM is a microscopic technique with atomic resolution and has been used widely in many fields of study. In 1986, a new type of microscopic technique was introduced, which analysis the surface of the sample using mechanical scanning without using any lens or photons. Since this microscopy operates using atomic forces, it is frequently called atomic force microscopy [60]. In fact, AFM provides information from images by "feeling" not from "looking" [61]. AFM can produce both 2D and 3D surface images simultaneously, while in the SEM technique, a 2D image is first obtained, and the 3D model is generated by its reconstruction. Moreover, there is no need for sample coating in the TEM technique and it can operate in both atmospheric and liquid environments [2]. Its main disadvantages are the limited imaging range and imaging speed [60]. Zhao et al. (2013) investigated the effect of the freeze-thaw process on the glutenin branch network by AFM. They found that ice crystal agitation resulted in the breakage of disulfide bonds, which weakened the glutenin network [45].

\subsection{Electromagnetic spectroscopic technique}

Techniques such as X-ray, near-infrared spectroscopy (NIR), nuclear magnetic resonance (NMR), Raman spectroscopy, and magnetic resonance imaging (MRI) do not cause sample damage, which is usually the case in other methods in the preparation step [2].

\subsubsection{X-ray computed tomography (X-ray CT)}

This technique is a non-destructive testing (NDT) technology which is employed to detect many hidden problems and even the entire information without sample separation and preparation [62]. This technology was invented by Godfrey N. Hounsfield and Allan M. Cormack in 1972, which is made by combining computer technology with X-ray technology.

Fig. 3 Cryo-SEM image of frozen apple by the microwaveassisted freezing process. $W$ cell wall and membrane structure, IC ice crystal, $A$ air space [13]

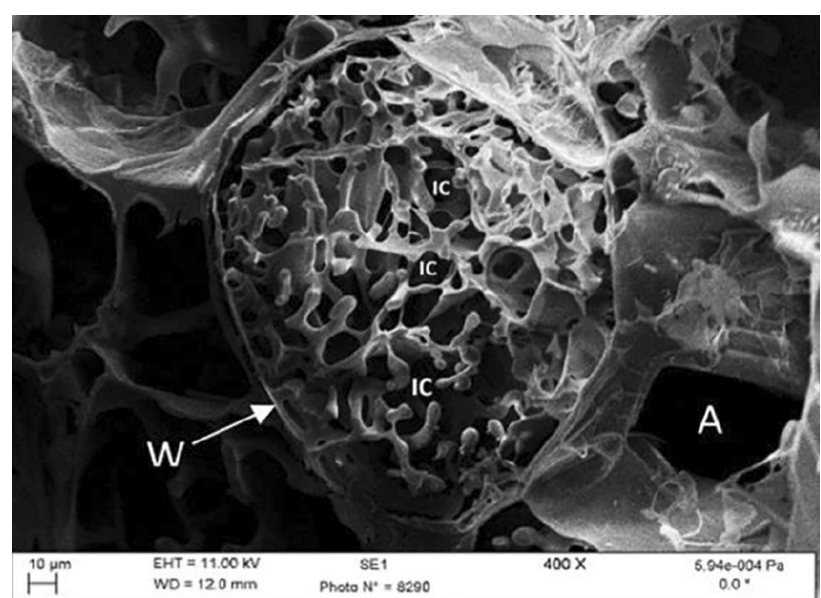


This equipment comprises three parts: the scanning part (consists of the X-ray source, detector and gantry), computer system, and image system [62].

$\mathrm{X}$-ray micro-computed tomography (X-ray $\mu \mathrm{CT}$ or micro-CT) is a non-invasive technique for imaging product structure with a minimum sample preparation [63]. Its principle is based on the contrast of the $X$-ray images generated by differences in X-ray attenuation arising principally from differences in density within the specimen. The obtained image is a projection of a volume in a two-dimensional plane. By $180^{\circ}$ rotating of the specimen, a large number of radiographs are generated and a 3D model is obtained. Mousavi et al. [64] used this technology to evaluate freeze-dried frozen foods' structure.

\subsubsection{Near infrared spectroscopy (NIR) spectroscopy}

Near infrared light is referred to light with a wavelength of 800 to $2500 \mathrm{~nm}$. This region is the first non-visible region in the absorption spectrum [65]. This technology is usually used for quality control of various materials especially cereal industry due to its advantages such as being rapid, chemical-free, non-destructive and easy to use method compared to other chemicals (for example, Kjeldahl and Soxhlet) and analytical (such as gas and high performance chromatography) methods. The spectra in the NIR region are generated due to energy absorption by organic molecules. These spectra contain the overtones and combinations of overtones, which are originated from the fundamental bond vibrations (stretching or bending) that occur in the mid-infrared (MIR) region of the spectrum [65]. The NIR spectroscopy only gives an average spectrum (average measurement) of the sample and does not count the scanned area of the sample. Since the collected spectra are averaged, giving a single spectrum, no information is obtained regarding the spatial distribution of the constituents within the sample. Therefore, the NIR hyperspectral imaging was developed to obtain both spatial (localization) and spectral (identification) information by combining the NIR spectroscopy with digital imaging. In a study conducted by the Cheng et al. (2018), the relationship between the size of ice crystals and the degree of structural deformation of frozen foods was obtained by NIR spectroscopy [66]. This relationship was obtained based on the effect of sample size, affected by the ice crystal size, on the absorption spectra.

The demand for fresh meat is higher than that for frozen meats and therefore, fresh meat has a higher price compared to frozen one. This attribute may cause some retailers to thaw the frozen meat and sell it as a chilled fresh product [67]. Due to the high similarity in the appearance of fresh and frozen-thawed meats, identifying fraudulent retailers can be quite a difficult task. The NIR hyperspectral imaging can detect the possible freeze-thaw process occurring during the storage of products specially meat. In a study, the thawing behavior of frozen chicken was investigated by the NIR spectroscopy. It was revealed that the melting of the ice crystal, protein proteolysis and the relaxation of lipids can be successfully identified by the variation in the spectral intensity of wavelength associated with $\mathrm{O}-\mathrm{H}, \mathrm{N}-\mathrm{H}$ and $\mathrm{C}-\mathrm{H}$ groups, respectively [68]. Sometimes by combining visible unit and NIR unit, forming a Vis-NIR hyperspectral imaging, the quality of frozen product at frozen state [69] and the effect of frozen/thawed on the quality [47] can be evaluated.

\subsubsection{Raman spectroscopy}

The physical principle of Raman spectroscopy is based on the inelastic scattering of light when it is impinged on the surface of a sample followed by measuring the frequency shift of reflected photons. By Collecting distinct Raman shifts due to light scattering, the chemical identity/structure of species are probed in a process as a molecular fingerprinting tool [70]. When a monochromatic light is radiated to a sample, a small proportion of the radiation is scattered depending on its physical and chemical properties. The interactions between the molecular vibrations and the laser light, a shift in energy between the incident and the scattered light are generated [71].

Raman microscopy is a combination of optical microscopy and Raman spectroscopy. Huen et al. (2014) investigated the microstructure of frozen bread dough using a confocal Raman microscopy [72]. Their results revealed that ice crystals in the frozen dough were in the form of a continuous phase rather than individual crystals. Wang et al., (2020) studied the effect of the freeze-thaw process on the properties of egg yolk during storage [73]. Raman spectroscopy analysis showed that the freeze-thaw process caused changes in secondary structures of egg yolk proteins. Chen et al., (2020) employed Raman spectroscopy to quantify the textural properties of beef affected by the freeze-thaw cycles [74]. Their results revealed that Raman spectroscopy could predict the changes in the tenderness, firmness, chewiness and hardness of beef caused by the freeze-thawing process. These studies showed that Raman spectroscopy can be applied successfully in the quality inspection of frozen food products. 


\subsubsection{Nuclear magnetic resonance (NMR) and magnetic resonance imaging (MRI)}

NMR spectroscopy is one of the most powerful analytical techniques that has received a high interest in food science. Initial applications of NMR that were applied in food science were limited to the low resolution NMR analysis of moisture. But later, at the end of the twentieth century, it was developed to high-resolution studies of liquid and solid food matrices for various purposes [75]. These included quality control, authentication and classification, structural and compositional analysis, understanding molecular mechanisms and interactions of food components, and the investigation of nutritional approaches to health. In NMR, 2D spectrum, in terms of different peaks in longitudinal and transverse relaxation time, the content and classes of water, including free water, bound water, and immobilized water can be reflected, providing information on content, distribution and fluidity of moisture in frozen foods. However, spatial images cannot be obtained by NMR; therefore, MRI which is a more advanced NMR equipment, is used for both relaxometry information and spatial spectroscopy [2].

During recent years, low-field nuclear magnetic resonance (LF-NMR) and MRI have been employed as powerful tools to characterize the water dynamic of food during processing and storage due to their non-invasiveness, fast analysis speed, sensitivity and low cost [76]. Many researchers have used these techniques to analyze the effect of freeze-thaw cycles on the quality of frozen products. Ali et al., (2015) reported that increasing the number of freeze-thaw cycles in the chicken breast resulted in a decrease in the transverse relaxation time of immobilized water [77]. Zhang et al., (2017) reported that after five freeze-thaw cycles of muscle, the three protons spin-spin relaxation time $\left(T_{2}\right)$ times were prolonged significantly than that of control samples [44]. This observation revealed that a portion of bound water in the cells changed into free water, and freeze-thaw cycles resulted in an increase in the mobility of free water, which could be related to the denaturation of proteins and redistribution of water caused by repeated freeze-thaw of ice crystals. Ice crystallization can significantly reduce the relaxation time $\left(T_{2}\right)$ and by this principle, unfrozen water of samples can be detected by the NMR SPRITE technique which is another method of obtaining water information [78]. In addition, MRI can be used for determining the glass transition temperature and ice formation (crystallization) in the freezing system [79]. In summary, NMR/MRI technology can be employed for rapid and dynamic monitoring of water conditions in order to improve the stability of frozen foods by optimizing process conditions [2].

Although conventional indirect assessment methods with high magnification are developed enough, sample pretreatment required in these techniques is damaging and slow. Therefore novel approaches must be explored to overcome these limitations. Combined technology can help monitor frozen food products' quality better and does not need excessive sample preparation. As a result, nondestructive and online assessment is a predictable trend in the future.

\subsubsection{Novel freezing techniques}

Novel freezing approaches (Table 2) have been applied to refine the limits of the traditional freezing method. Emerging freezing techniques generate finer and homogenously distributed ice crystals, enhance freezing rates, and suppress nucleation. Thus, understanding the mechanisms and impacts of innovative freezing is significant. Table 2 shows the novel freezing methods aimed at controlling ice nucleation and subsequent ice crystal growth during freezing.

\subsection{Ultrasound-assisted freezing}

Ultrasound power is a novel, green, and non-polluting process in both the analysis and preservation of food in the field of the freezing process. Propagating ultrasound waves within fluids medium causes cavitation, resulting in acoustic bubbles produced. Collapse and motion of cavitation bubbles make microstremeanig effect [81, 101, 102], leading to increase convective heat transfer rate $[5,103]$ and mass transfer rate [4]. The cavitation and microstreaming effect $[80]$ enhances nucleation probability in supercooled water and induces nucleation at higher temperatures during the freezing process [89]. Cavitation bubbles that are produced by power ultrasound can serve as ice nuclei in the primary ice nucleation step [1], and improve secondary nucleation by the breakage of parent ice crystals [82]. Therefore, Ultrasound-assisted freezing triggers the freezing process and produces uniform ice crystals, reducing structural damages of frozen food materials [7, 104].

Ultrasound-assisted freezing is divided into three types of full immersion, half immersion, and non-immersion (direct contact) (Fig. 4) [1]. Zhang, Xia [5] evaluated the effects of full immersion freezing by ultrasound on the porcine longissimus muscles. They indicated that ultrasound freezing at $180 \mathrm{~W}$ and $30 \mathrm{kHz}$ makes smooth, small, and evenly distributed ice crystals during freezing and the frozen storage of meat. Also, the time of the process was decreased 


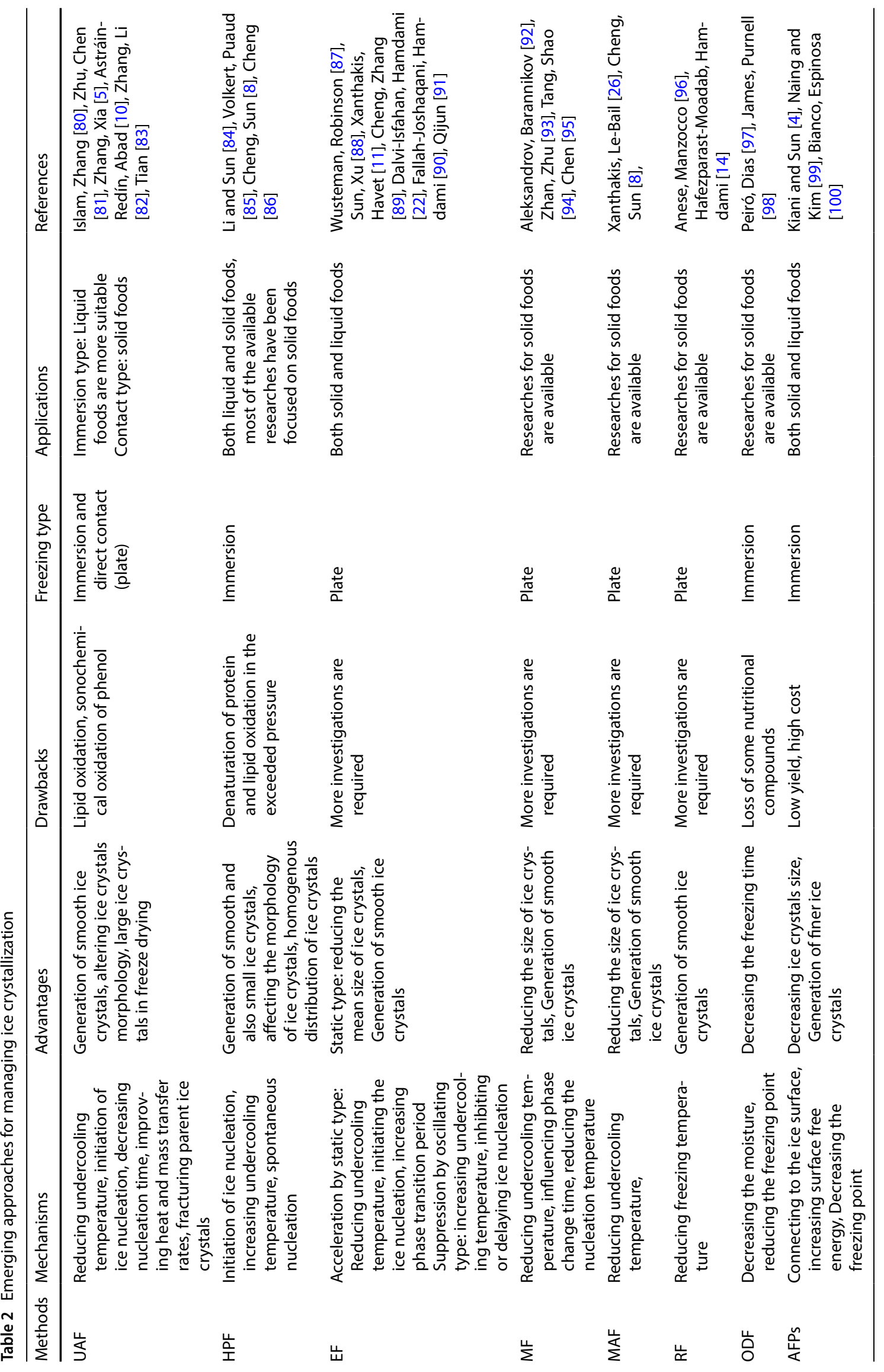


by $12.6 \%$. The crystals' size has been less increased by the time compared to other freezing methods (air freezing and immersion freezing). Zhang, Li [82] compared the ultrasound full immersion freezing (different power levels, and $20 \mathrm{kHz}$ frequency with an interval of $5 \mathrm{~s}$ ultrasound and $5 \mathrm{~s}$ off-time) with the traditional immersion freezing in the dough. They found that the ultrasound freezing is shorter (577 s). Besides, the sulfhydryl content of gluten was increased $(12 / 06 \%)$, and the surface hydrophobicity of gluten was higher (19/67\%) by the use of ultrasound treatment. Results were indicated that the maximum ice crystals generation zone $\left(0^{\circ} \mathrm{C}\right.$ to $\left.-5^{\circ} \mathrm{C}\right)$ was significantly affected by ultrasound waves resulting in power ultrasound was enhanced the formation of nuclei and accelerating crystal growth. Moreover, FTIR results showed that the secondary structure of gluten, glutenin, and gliadin was changed and more ordered compared to control samples, and samples were treated by immersion freezing.

To our knowledge, only a few studies have been applied direct contact ultrasound, while most studies having been widely employed ultrasound whole and half immersion. Direct ultrasound freezing is a method without a liquid medium. Due to the improbably produced cavitation bubbles, direct cavitation causes fewer destructive damages, such as decreasing lipid oxidation on foods [10]. Astráin-Redín, Abad [10] evaluated non-immersion ultrasound freezing of chicken breasts $(40 \mathrm{kHz}$ and 50$)$. They reported that intermittent acoustic treatment with a net sonication time of $37 \%$ decreased approximately $11 \%$ of elapsed time. Also, the samples' freezing curves indicate that the initial time of precooling for removing sensible heat and the time of the second stage of freezing, including the phase change stage to the removal of latent heat, are reduced (Fig. 5). Furthermore, there are no differences between treated meats and untreated ones regarding water holding capacity (WHO) and in vitro protein digestibility. In another study, Islam, Zhang [105] also used direct contact ultrasound freezing ( $300 \mathrm{~W}$ and $20 \mathrm{kHz}$ ) and reported that ultrasound treated frozen mushrooms have smaller (0-80 microns, while control samples were 50-180 microns) ice crystals resulting in improving in samples quality.

Power ultrasound-assisted freezing has also been examined in several types of food comprising apple [106], Red bell pepper [107], strawberry [19], broccoli [108], Wrapped Red Radish [23], common carp [109], and potato [104, $110,111]$ as a promising method for improving the parameters of the freezing process and enhancing the quality of the foods. Furthermore, ultrasound-assisted freezing has been demonstrated its ability to initiate the formation of nuclei in supercooled solid and liquid model foods, including water [112], deionized water, and sucrose solution [113], as well as agar gel samples [7, 114].
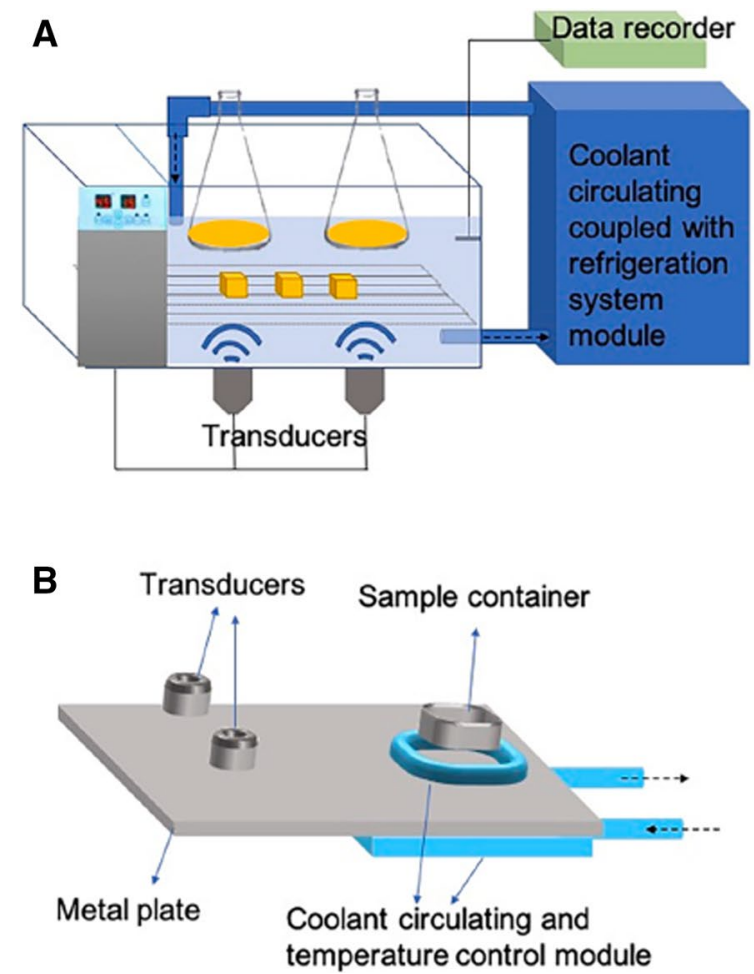

C

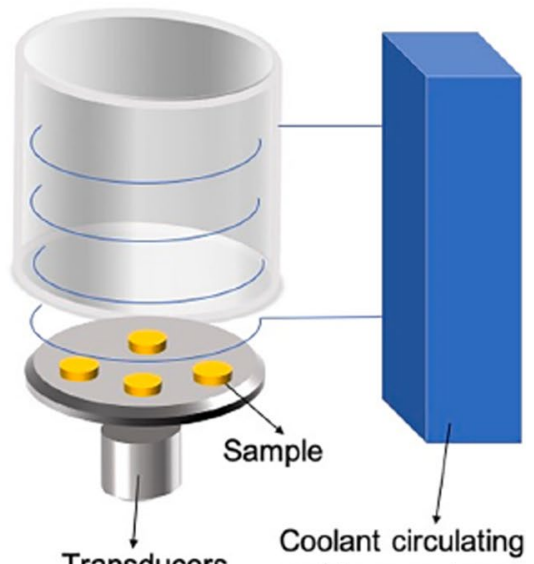

Transducers control module

Fig. 4 Three types of ultrasound apparatus, A: full immersion, B: half immersion, and C: non-immersion (direct contact) [1] 
Fig. 5 Freezing curves of chicken breasts were treated by ultrasound freezing (Blue squared box) at (3 s on / $5 \mathrm{~s}$ off during freezing) and untreated chicken breasts (Orange squared box) [10]

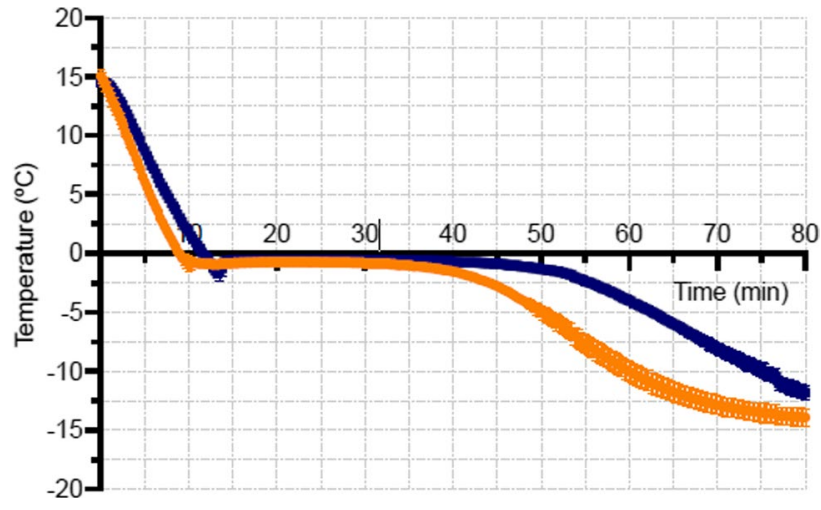

\subsection{High hydrostatic pressure freezing}

The use of high hydrostatic pressure as non-thermal technology has been enhanced in food processing, also in the field of food freezing. High pressure treatment inactivates endogenous enzymes and spoilage microorganisms, retaining the quality of foods $[115,116]$. From $100 \mathrm{Mpa}$ up to higher pressure levels, microbial growth is inhibited under high pressure [117].

The freezing point of water is changed under the high amount of hydrostatic pressure (Fig. 6), so that the freezing point is decreased with the increase of pressure while reducing the pressure has a reverse effect on phase change temperature. For instance, the freezing point of water can be reduced with hydrostatic pressure from $0{ }^{\circ} \mathrm{C}$ at $0.1 \mathrm{MPa}$ to $-21^{\circ} \mathrm{C}$ at $210 \mathrm{MPa}$ (water liquid zone below $0{ }^{\circ} \mathrm{C}$ under high hydrostatic pressure) $[4,84,118]$.

As shown in Fig. 6, ice crystals may have different types (I-VI), ice I is formed in the atmospheric pressure, and its density is lower than liquid water, resulting in a volume increase by ice I cause damage to the tissues of food materials. Under high pressure, several types of ice crystals (II-VI) are formed, with a higher density than that of water, leading to less damage during freezing by high hydrostatic pressure $[84,119,120]$.

Based on the different crystallization paths and ice crystal types, high-pressure freezing (HPF) is divided into three main categories, high-pressure assisted freezing (PAF), high-pressure induced freezing (PIF), and high-pressure shift freezing (PSF), in which due to the smaller phase change time and a larger amount of supercooling degree achieved after expansion, also lacking the thermal gradient, PSF has been more employed than that other types of pressure freezing $[2,8,121,122]$

As presented in Fig. 6 , the PAF process includes decreasing the temperature (to $-20^{\circ} \mathrm{C}$ ) of foods under constant pressure $(200 \mathrm{MPa})$ to their phase change point, while PSF briefly consists of increasing the pressure upper the initial freezing point of samples and suddenly releasing the pressure, leading to induce nucleation [84, 118]. In PIF, the phase change begins with increased pressure, and the process remains at a constant pressure. Overall, PIF needs higher pressure than that in both PSF and PAF, leading to less applicability. Furthermore, PIF is not easy to operate [123].

It has been well documented that high pressure freezing can enhance the quality of different food materials, such as carrot, mango, peach, turbot, potato, sea bass, Norway lobster, etc. Due to the high supercooling reached on pressure release, resulting in the promotion of nucleation and instantaneous formation of homogenously distributed ice crystals $[10,104,124-127]$. Choi, Min [128] evaluated the effect of PSF on the quality of pork and found that PSF at 50 MPa had

Fig. 6 Phase diagram of water: (ABCD: high pressure assisted freezing, ABEFG: high pressure shift freezing, ABEFHI: high pressure induced freezing) [118]

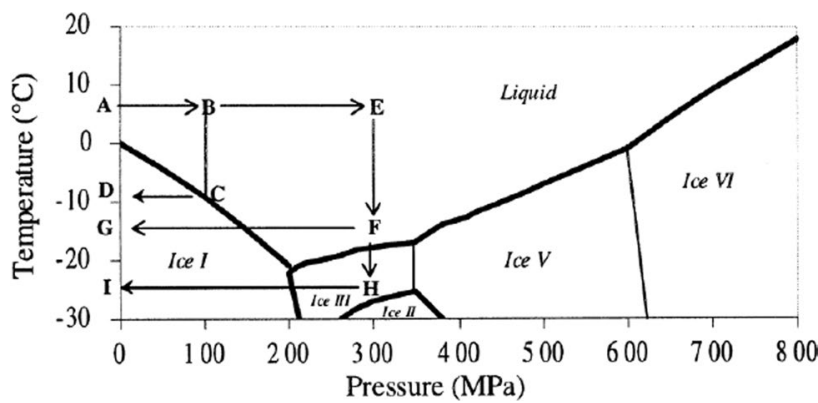


no positive impact on the quality of pork as compared to atmospheric $(0.1 \mathrm{MPa})$ freezing, while PSF treatment at higher pressure than $150 \mathrm{MPa}$ showed quality deterioration including drip loss and discoloration. On the other hand, PSF at $100 \mathrm{MPa}$ was the best treatment due to the similar quality with unfrozen control samples.

High pressure treatment causes some damages in the foods [129, 130], as Hsu, Hwang [131] reported that the high hydrostatic pressure upper at $100 \mathrm{MPa}$ promoted the aggregation and disruption of actomyosin of tilapia due to the formation of hydrogen bonds. Furthermore, Volkert, Puaud [85] found that $\operatorname{HPF}\left(300 \mathrm{MPa},-16^{\circ} \mathrm{C}\right)$ caused a minor denaturation (3\%) in the milk protein. Cheng, Sun [123] evaluated the effect of PAF and PSF as compared to immersion freezing on the denaturation of actomyosin extracted from prawn, showing that PSF at $200 \mathrm{Mpa}$ and $-20^{\circ} \mathrm{C} / 30 \mathrm{~min}$ reduced the denaturation of actomyosin, also $300 \mathrm{MPa}$ was introduced as a critical value of HPF process that was promoted denaturation. Results showed that HPF did not affect on the primary structure of actomyosin, whereas the secondary and tertiary structure of actomyosin was changed by HPF treatment.

\subsection{Electrically disturbed freezing}

The electric field is divided into two types, including the oscillating electric field (OEF) and the static electric field (SEF) [132]. OEF is commonly used for dielectric heating because of the rotation of water dipole molecules in the electric field, while high voltage SEF can be used as a freezing assistant. In the freezing process, owing to the redistribution of water molecules, resulting in the increasing supercooling degree in the presence of a static electric field, OEF serves as a suppression method $[87,89]$. Under the presence of the electric field, the dipole structure of water molecules is redirected along the electric field, which the amount of the redirected water molecules is called polarizability. Water has known as a high polarizable liquid $[133,134]$. The polarization and reorientation of water molecules in the presence of the static electric field (under direct current (DC) electric) causes hydrogen bonds to be stronger, resulting in the structure of water clusters being changed, and a more ordered cluster structure is formed [88, 89, 135]. Consequently, the gibs free energy of the whole system is decreased [2].

SEF can initiate ice nucleation $[10,88,136,137]$, increasing the temperature of ice nucleation $[90,138]$, decreasing the undercooling degree [139], reducing the mean size of ice crystals [11,22], as well as increasing phase transition period (crystallization time) [24,90], while OEF inhibits or postpones the formation of ice nuclei [2]. The magnitude of the used SEF is directly related to the supercooling degree and ice crystal size $[11,24,139]$. The shape and material of electrodes can affect the induction of nucleation by SEF. The aluminum electrode [140], and flat end surface electrode [141], showed the lowest supercooling degree among other shapes and materials.

SEF under alternating electric (AC) field has been less investigated than in DC. SEF under DC electric field may delay nucleation initiation and increase subcooling temperature [136].

\subsection{Magnetically disturbed freezing}

Differences in voltage produce an electric field, while the magnetic field is formed when electric current flows. Like the electric field, the magnetic field is also divided into two types, comprising the oscillating magnetic field (OMF) and static magnetic field (SMF) [132]. OMF is also commercially known as CAS (Cells Alive System) freezer. OMF is produced by permanent magnets, while SMF is generated by magnetic coils [142].

Materials with magnetocaloric properties are suitable for freezing under the magnetic field [92]. Due to the lack of intrinsic magnetic dipole moment (diamagnetic property), in the presence of a magnetic field, hydrogen bonds of water will be stronger, well-distributed, and stable, leading to an increase in melting temperature and heat transfer rate [89, 143], as well as affect on freezing behavior [144]. The optimization and employing proper strength of the magnetic field is controversial. Otero, Rodríguez [145] indicated that a 0.8-mT OMF did not affect the supercooling degree and freezing kinetics of pure water and $0.9 \% \mathrm{NaCl}$ solution. Moreover, under the weak (107-359 mT) SMF, no significant effects were reported by Otero, Rodríguez [146]. Similar deductions were drawn for the low-strength OMF [147-149]. Nevertheless, some researchers reported that weak OMF affected the freezing process. For instance, Zhan, Zhu [93] demonstrated that the supercooling degree of $9 \mathrm{~g} / \mathrm{L}$ sodium chloride solution was reduced in the presence of a $10 \mathrm{mT} O M F$. Tang, Shao [94] evaluated the effects of OMF and SMF on the freezing of blueberry. Results showed that the SMF decreased the nucleation temperature and average ice crystal size, while OMF just increased phase change time and had no significant effect on the other freezing parameters. Tang, Zhang [12] reported that $10 \mathrm{mT}$ and $1.26 \mathrm{mT}$ were the optimum strength of the magnetic field for SMF and OMF, respectively. They found that the phase change time was decreased under SMF, while it was increased with OMF. Moreover, smaller and uniformly intracellular ice crystals were observed 
with both OMF and SMF. Results have shown that the magnetic field may not affect all food systems in the same way, and more investigation will be required.

\subsection{Microwave-assisted freezing}

Due to the water dipole moments, microwaves can affect the freezing process [89]. MAF decreased supercooling temperature and the mean size of ice crystals in the frozen pork samples compared to the conventional freezing process [26]. Jha, Chevallier [13] found that MAF did not affect the freezing parameters (freezing rates, and the overall freezing time) of apple and potato samples. In contrast, the quality parameters (texture, drip loss) were improved in both apple and potato under the MAF. Sadot, Curet [150] reported an up to $25 \%$ reduction in the size of ice crystals under both pulsed and constant MAF in methylcellulose gels.

\subsection{Radiofrequency freezing}

MAF and RF are two types of electromagnetic assisted freezing. In the presence of radiofrequency waves, water dipole rotation can affect the crystallization behavior of ice crystals [89]. Anese, Manzocco [96] demonstrated that RF frozen pork meat samples had smaller and intracellular ice crystals, due to applying RF decreased the freezing point results in more nucleation sites. Results showed that the microstructure of treated meat by RF had better cellular integrity than that in air and cryogenic frozen meat. Hafezparast-Moadab, Hamdami [14] investigated the effects of RF on the freezing process and quality attributes (drip loss, colour, texture, and microstructure) of rainbow trout fish as compared to the air blast freezing technique, showing that the RF-frozen fish had smaller drip loss and ice crystals (up to $75 \%$ smaller), also ice crystals were uniformly distributed under RF treatment. Moreover, there was no significant difference between RF samples and unfrozen samples in colour, as well as textural properties including hardness, gumminess, and chewiness.

\subsection{Osmo-dehydro-freezing}

A large amount of water in the fruits and vegetables can inhibit and postpone the freezing process. In order to remove a large amount of water, air drying [151], pulsed electric fields, vacuum drying [152], vacuum-microwave drying [153], and osmotic dehydration have been investigated as drying pretreatment prior to freezing. Osmotic dehydration is a proper way to decrease moisture content, leading to easier freezing. Osmo-dehydro-freezing is an integrated process, consisting of two separate stages, including osmotic dehydration and subsequently freezing [8, 154]. Compared with air drying (as a pretreatment for freezing), osmotic dehydration need less energy [84].

Sucrose (the most utilized carbohydrate) [155], glucose [156], sorbitol [157], maltose [158], $\mathrm{NaCl}$ [159] have been employed as common hypertonic solutes in osmotic dehydration. Temperature, process time, composition, and concentration of the hypertonic solutes are the main useful parameters in osmo-dehydro-freezing [154]. As stated in [160], sucrose showed higher firmness in both 3 and 60 days of storage time than maltitol and trehalose. However, all the osmotic solutions had the same values in water loss and solid gain. In another study, the comparison of sorbitol, maltitol, and sucrose was investigated by [161]. They reported that vitamin c was better preserved by maltose, also compared with sucrose and maltitol, the color stability effect of maltose was higher. However, the pre-treated apricots with $65 \%$ sorbitol had a higher water loss and solid gain than those samples that were pretreated with maltose and sucrose solutions.

Osmotic dehydration prior to freezing decreases the freezing time, the initial freezing point, as well as the number of ice crystals may be reduced under dehydration pretreatment [98]. In order to enhance the efficiency of osmotic dehydration pretreatment [98], the combination of osmotic dehydration with other novel technologies like pulsed electric fields [162], blanching [163], vacuum treatments [98], and ultrasound have been investigated. Fan, Zhang [16] indicated that the combination of the osmotic dehydration by the ultrasonic process $(20 \mathrm{kHz}, 0-300 \mathrm{~W})$ before freezing increased water loss and solid gain. Also, the structure of kiwifruits was better maintained, compared to the osmotic dehydration alone.

\subsection{Proteins}

Biological proteins have shown a contrasting behavior in the freezing process, including antifreeze and nucleating agents. The most important difference between ice nucleating proteins and antifreeze proteins may be their molecular sizes [17]. Due to the extremely low temperature in antarctic and arctic regions, antifreeze proteins have been employed by the organisms as a self-protection survival strategy [164]. Antifreeze proteins have been introduced in some diverse 
sources, such as bony fish (the earliest research was in 1969) [165], insecta (alaskan insects) [166], plantae (hippophae rhamnoides) [167], fungi (snow molds) [168], nematode (panagrolaimus davidi) [169], amphibian (rana sylvatica) [170], bacteria (pseudomonas putida) [171], and sea ice diatoms [172].

AFPs are defined as biological antifreeze agents, which irreversibly pin to the surface of ice crystals, leading to hinder the growth and modify the formation of ice crystals [173]. The difference between the freezing point and the melting point is defined as thermal hysteresis [174]. AFPs are categorized based on thermal hysteresis value to demonstrate their level of antifreeze activity. Plants and Fish have moderate (low thermal hysteresis values, $0.2-0.6^{\circ} \mathrm{C}$ and $1-2{ }^{\circ} \mathrm{C}$ ) AFPs, while AFPs are derived from insects and bacteria are hyperactive (higher thermal hysteresis values, $\left.5-10^{\circ} \mathrm{C}\right)[99,173,176,177]$.

The Fish derived AFPs are the most applied antifreeze proteins [173], which are classified as type I (alanine-rich proteins) [178], type II (cysteine-rich globular proteins) [179], type III (globular proteins) [180], type IV, and antifreeze glycoproteins (AFGPs) (repeat-tripeptide, besides a disaccharide on every third amino acid) [181]. Due to easier production through recombinant genes, the majority of applied AFPs are type III [173].

It is widely documented that AFPs could enhance the quality and improve the sensory evaluation of frozen foods, even with low-concentration $[2,173]$. Soaking (before freezing) the bovine muscle in AFPs derived from the Antarctic cod decreased freeze damage to the muscle. Ice intracellular crystals in the treated muscles were smaller than those in untreated muscles. AFPs did not affect the chilled meat [182]. Compared with conventional cryoprotectants (sucrosesorbitol mixture), type III AFPs significantly retained the activity of $\mathrm{Ca}^{2+}$ ATPase of frozen and chilled actomyosin, resulting in a better gel-forming property. Moreover, the effect of AFPs depended upon the concentration of AFPs [183]. Chen and Wang [184] reported the freeze avoidance effect of antifreeze glycopeptide analogs on Streptococcus thermophilus in yogurt. The viability of Streptococcus thermophiles increased up to $92.56 \%$ in the presence of antifreeze agents $(5 \mathrm{mg} /$ $\mathrm{mL}$ ). AFPs not only decreased drip loss but also preserved the color, total anthocyanin, and antioxidant content of frozen cherries [185]. AFPs have also been investigated during freezing food samples, including gluten proteins [186], dough [187, 188], starch solution, milk, and orange juice [189], ice cream [190, 191], pasta sauces [192], and carrot [193].

Some biological proteins served as nucleators in the crystallization, promoting ice nucleation by increasing the freezing point [2] and changing the ice formation patterns [194]. The size, quality, and quantity of the INAs affect the ice nucleation temperature of ice nucleating agents (INAs) [195]. INAs were detected in bacteria, insects, plants, intertidal invertebrates, and lichen [4]; besides, $\mathrm{Agl}$ and $\mathrm{Pbl}_{2}$ are defined as ice nucleating agents [2]. It has been found that INAs can be useful for plants to survive at sub-zero temperatures [195].

It has been reported that the addition of INAs to foods bring numerous benefits, including increasing ice nucleation temperature, decreasing the freezing period, elevating freezing rate, thereby enhancing the quality of frozen foods, and reducing the cost of the freezing process $[4,196,197]$. By the addition of bacterial INPs, the flavor, color, and texture of some liquid foods were improved [198]; also, the freezing efficiency of a liquid model food was enhanced [199], as well as the mean size of ice crystals was reduced from $25.7 \mu \mathrm{m}$ to $15 \mu \mathrm{m}$ in the solid model food [196]. Jin, Yurkow [200] showed that the use of ice nucleating proteins isolated from Erwinia herbicola subsp. Ananas enhanced the efficiency of freeze drying of a $10 \%$ sucrose solution (liquid food model) due to an increased primary drying rate. Also, total energy saving was increased up to $28.5 \%$ by using INPs.

As the freezing assisted by physical fields is still not well recognized, much study is essential to improve process parameters and discover the possible applications of these technologies to foodstuff. Experimental reproducibility is always a problem because of the instability of electromagnetic fields, and the available results are even contradictory. As a result, great efforts should be made to confirm their practicability and interpret results to apply these novel technologies to control ice crystallization.

\section{Conclusion}

In this review, the principles of water crystallization were introduced, modeling of ice nucleation and subsequent ice crystal growth was revealed, evaluation methods to visualize and monitor the crystallization phenomena were presented. Finally, the novel freezing methods and their effects on crystallization and food samples were revealed. Various studies have demonstrated that new freezing technologies, including ultrasound, high pressure, microwave, antifreeze proteins, etc., can control the ice nucleation and ice crystal growth to form well distributed, intracellular and small ice crystals. Homogenous and small ice crystals are desired in most frozen foods, leading to minor damage to the structure of frozen food materials. These promising results have encouraged researchers to incorporate in the investigation of more studies about water crystallization. On the other hand, most of these technologies are in trial steps. Much work is 
needed to investigate the mechanism and optimize technological parameters to translate laboratory results to industrial applications. For acquiring more comprehensive and accurate sample information, the emergence of online techniques makes in-situ detection a reality. We hope that the information documented herein will broaden the understanding of crystallization and its importance in food materials.

Authors' contributions EP: Conceptualization, Investigation, Visualization, Writing- Original draft preparation. MP: Writing一original draft. HK: Review and editing. All authors have read and agreed to the published version of the manuscript. All authors read and approved the final manuscript.

Funding This research did not receive any specific grant from funding agencies in the public, commercial, or not-for-profit sectors.

\section{Declarations}

Competing interests The authors declare that they have no competing or conflict of interests.

Open Access This article is licensed under a Creative Commons Attribution 4.0 International License, which permits use, sharing, adaptation, distribution and reproduction in any medium or format, as long as you give appropriate credit to the original author(s) and the source, provide a link to the Creative Commons licence, and indicate if changes were made. The images or other third party material in this article are included in the article's Creative Commons licence, unless indicated otherwise in a credit line to the material. If material is not included in the article's Creative Commons licence and your intended use is not permitted by statutory regulation or exceeds the permitted use, you will need to obtain permission directly from the copyright holder. To view a copy of this licence, visit http://creativecommons.org/licenses/by/4.0/.

\section{References}

1. Fu X, et al. Sono-physical and sono-chemical effects of ultrasound: Primary applications in extraction and freezing operations and influence on food components. Ultrason Sonochem. 2020;60:104726.

2. Zhu Z, Zhou Q, Sun D-W. Measuring and controlling ice crystallization in frozen foods: a review of recent developments. Trends Food Sci Technol. 2019;90:13-25.

3. Sadot $M$, et al. Numerical modelling of an innovative microwave assisted freezing process. Int J Refrig. 2017;80:66-76.

4. Kiani H, Sun D-W. Water crystallization and its importance to freezing of foods: a review. Trends Food Sci Technol. 2011;22(8):407-26.

5. Zhang $\mathrm{M}$, et al. Changes in microstructure, quality and water distribution of porcine longissimus muscles subjected to ultrasound-assisted immersion freezing during frozen storage. Meat Sci. 2019;151:24-32.

6. Luo W, et al. Improving freeze tolerance of yeast and dough properties for enhancing frozen dough quality a review of effective methods. Trends Food Sci Technol. 2018;72:25-33.

7. Kiani H, Zhang Z, Sun D-W. Effect of ultrasound irradiation on ice crystal size distribution in frozen agar gel samples. Innov Food Sci Emerg Technol. 2013;18:126-31.

8. Cheng L, et al. Emerging techniques for assisting and accelerating food freezing processes: a review of recent research progresses. Crit Rev Food Sci Nutr. 2017;57(4):769-81.

9. Islam, M.N., M. Zhang, and B. Adhikari, Ultrasound-assisted freezing of fruits and vegetables: design, development, and applications, In: Global food security and wellness. Springer; 2017, 457-487. https://doi.org/10.1007/978-1-4939-6496-3_22

10. Astráin-Redín L, et al. Direct contact ultrasound assisted freezing of chicken breast samples. Ultrason Sonochem. 2020. https://doi.org/ 10.1016/j.ultsonch.2020.105319.

11. Xanthakis $E$, et al. Effect of static electric field on ice crystal size reduction during freezing of pork meat. Innov Food Sci Emerg Technol. 2013;20:115-20.

12. Tang J, et al. Effects of different magnetic fields on the freezing parameters of cherry. J Food Eng. 2020;278:109949.

13. Jha PK, et al. Effect of innovative microwave assisted freezing (MAF) on the quality attributes of apples and potatoes. Food Chem. 2020;309:125594.

14. Hafezparast-Moadab N, et al. Effects of radiofrequency-assisted freezing on microstructure and quality of rainbow trout (Oncorhynchus mykiss) fillet. Innov Food Sci Emerg Technol. 2018;47:81-7.

15. Pita-Calvo C, et al. High-pressure processing before freezing and frozen storage of European hake (Merluccius merluccius): effect on mechanical properties and visual appearance. Eur Food Res Technol. 2018;244(3):423-31.

16. Fan $\mathrm{K}$, et al. A novel method of osmotic-dehydrofreezing with ultrasound enhancement to improve water status and physicochemical properties of kiwifruit. Int J Refrig. 2020;113:49-57.

17. Eickhoff $\mathrm{L}$, et al. Contrasting behavior of antifreeze proteins: Ice growth inhibitors and ice nucleation promoters. J Phys Chem Lett. 2019;10(5):966-72.

18. Usman M, Khan S, Lee J-A. Afp-LSe: Antifreeze proteins prediction Using Latent Space encoding of composition of k-Spaced Amino Acid pairs. Sci Rep. 2020;10(1):1-13.

19. Cheng $X-F$, et al. Effect of ultrasound irradiation on some freezing parameters of ultrasound-assisted immersion freezing of strawberries. Int J Refrig. 2014;44:49-55. 
20. Lagnika C, Zhang M, Mothibe KJ. Effects of ultrasound and high pressure argon on physico-chemical properties of white mushrooms (Agaricus bisporus) during postharvest storage. Postharvest Biol Technol. 2013;82:87-94.

21. O'donnell C, et al. Effect of ultrasonic processing on food enzymes of industrial importance. Trends Food Sci Technol. 2010;21(7):358-67.

22. Dalvi-Isfahan M, Hamdami N, Le-Bail A. Effect of freezing under electrostatic field on the quality of lamb meat. Innov Food Sci Emerg Technol. 2016;37:68-73.

23. Xu B-G, et al. Effect of ultrasound immersion freezing on the quality attributes and water distributions of wrapped red radish. Food Bioprocess Technol. 2015;8(6):1366-76.

24. Jia G, et al. Effects of high-voltage electrostatic field on the freezing behavior and quality of pork tenderloin. J Food Eng. 2017;204:18-26.

25. Li K, et al. Effect of ultrasound treatment on functional properties of reduced-salt chicken breast meat batter. J Food Sci Technol. 2015;52(5):2622-33.

26. Xanthakis E, Le-Bail A, Ramaswamy H. Development of an innovative microwave assisted food freezing process. Innov Food Sci Emerg Technol. 2014;26:176-81.

27. Russo Krauss I, et al. An overview of biological macromolecule crystallization. Int J Mol Sci. 2013;14(6):11643-91.

28. Morris GJ, Acton E. Controlled ice nucleation in cryopreservation-a review. Cryobiology. 2013;66(2):85-92.

29. Rupp, B., Biomolecular crystallography: principles, practice, and application to structural biology. Garland Science, 2009

30. McPherson A. Introduction to protein crystallization. Methods. 2004;34(3):254-65.

31. Brittain HG. Polymorphism in pharmaceutical solids. Drugs the pharmaceutical sciences, vol 95; 1999. p. 183-226

32. Banga S, Chawla G, Bansal AK. New trends in the crystallization of active pharmaceutical ingredients. Business Briefing. 2004;6:70-4.

33. Mullin, J.W., Crystallization. Elsevier; 2001.1016/B978-075064833-2/50009-7

34. Kashchiev D, Van Rosmalen G. Nucleation in solutions revisited. Cryst Res Technol. 2003;38(7-8):555-74.

35. Volmer, M., \& Weber, A, Keimbildung in ubersattigten Losungen. Zeitschrift fur Physikalische Chemie 1926;277:119.

36. Mersmann, A., Crystallization technology handbook. CRC press; 2001. https://doi.org/10.1201/9780203908280

37. Turnbull, D., Phase changes, In: Solid state physics. Elsevier; 1956, 225-306. https://doi.org/10.1016/S0081-1947(08)60134-4

38. Turnbull D, Fisher JC. Rate of nucleation in condensed systems. J Chem Phys. 1949;17(1):71-3.

39. Zaritzky, N., Physical-chemical principles in freezing. In: Handbook of frozen food processing and packaging, 2011. 2. https://doi. org/10.1201/b11204-3

40. Leygonie C, Britz TJ, Hoffman LC. Impact of freezing and thawing on the quality of meat. Meat Sci. 2012;91(2):93-8.

41. Dirksen J, Ring T. Fundamentals of crystallization: kinetic effects on particle size distributions and morphology. Chem Eng Sci. 1991;46(10):2389-427.

42. Nielsen AE. Theory of electrolyte crystal growth. The parabolic rate law. Pure Appl Chem. 1981;53(11):2025-39.

43. Kiani H, Sun D-W. Numerical simulation of heat transfer and phase change during freezing of potatoes with different shapes at the presence or absence of ultrasound irradiation. Heat Mass Transf. 2018;54(3):885-94.

44. Zhang $\mathrm{M}$, et al. Moisture migration, microstructure damage and protein structure changes in porcine longissimus muscle as influenced by multiple freeze-thaw cycles. Meat Sci. 2017;133:10-8.

45. Zhao L, et al. Effect of freeze-thaw cycles on the molecular weight and size distribution of gluten. Food Res Int. 2013;53(1):409-16.

46. Landis EN, Keane DT. X-ray microtomography. Mater Charact. 2010;61(12):1305-16.

47. Reis $M$, et al. Non-invasive differentiation between fresh and frozen/thawed tuna fillets using near infrared spectroscopy (Vis-NIRS). LWT. 2017;78:129-37.

48. Rostron P, Gaber S, Gaber D. Raman spectroscopy, review. Laser. 2016;21:24.

49. Caillet A, et al. Characterization of ice cream structure by direct optical microscopy. Influence of freezing parameters. LWT Food Sci Technol. 2003;36(8):743-9.

50. Donhowe D, Hartel R, Bradley R Jr. Determination of ice crystal size distributions in frozen desserts. J Dairy Sci. 1991;74(10):3334-44.

51. Faydi E, Andrieu J, Laurent P. Experimental study and modelling of the ice crystal morphology of model standard ice cream. Part I: direct characterization method and experimental data. J Food Eng. 2001;48(4):283-91.

52. Ninagawa T, et al. A study on ice crystal formation behavior at intracellular freezing of plant cells using a high-speed camera. Cryobiology. 2016;73(1):20-9.

53. Dai C, et al. Influence of ultrasound-assisted nucleation on freeze-drying of carrots. Drying Technol. 2016;34(10):1196-203.

54. Kuo J. Electron microscopy: methods and protocols, vol. 369. Berlin: Springer Science \& Business Media; 2007.

55. Donald AM. The use of environmental scanning electron microscopy for imaging wet and insulating materials. Nat Mater. 2003;2(8):511-6.

56. Weston AE, Armer HE, Collinson LM. Towards native-state imaging in biological context in the electron microscope. J Chem Biol. 2010;3(3):101-12.

57. Efthymiou C, Williams MA, McGrath KM. Revealing the structure of high-water content biopolymer networks: diminishing freezing artefacts in cryo-SEM images. Food Hydrocolloids. 2017;73:203-12.

58. Lili W, Yeming C, Zaigui L. The effects of freezing on soybean microstructure and qualities of soymilk. J Food Eng. 2013;116(1):1-6.

59. Phothiset $\mathrm{S}$, Charoenrein $\mathrm{S}$. Effects of freezing and thawing on texture, microstructure and cell wall composition changes in papaya tissues. J Sci Food Agric. 2014;94(2):189-96.

60. Yang $\mathrm{H}$, et al. Application of atomic force microscopy as a nanotechnology tool in food science. J Food Sci. 2007;72(4):R65-75.

61. Morris, V.J., A.R. Kirby, and A.P. Gunning, Atomic force microscopy for biologists, Vol. 57. World Scientific, 1999. https://doi.org/10.1142/ p173

62. Du Z, et al. X-ray computed tomography for quality inspection of agricultural products: a review. Food Sci Nutr. 2019;7(10):3146-60.

63. Jha PK, et al. Assessment of freeze damage in fruits and vegetables. Food Res Int. 2019;121:479-96.

64. Mousavi R, et al. Imaging food freezing using X-ray microtomography. Int J Food Sci Technol. 2007;42(6):714-27.

65. Schudel S, Prawiranto K, Defraeye T. Comparison of freezing and convective dehydrofreezing of vegetables for reducing cell damage. J Food Eng. 2020;293:110376. 
66. Cheng W, et al. Characterization of myofibrils cold structural deformation degrees of frozen pork using hyperspectral imaging coupled with spectral angle mapping algorithm. Food Chem. 2018;239:1001-8.

67. Barbin DF, Sun D-W, Su C. NIR hyperspectral imaging as non-destructive evaluation tool for the recognition of fresh and frozen-thawed porcine longissimus dorsi muscles. Innov Food Sci Emerg Technol. 2013;18:226-36.

68. Liu Y, Chen Y-R. Two-dimensional visible/near-infrared correlation spectroscopy study of thawing behavior of frozen chicken meats without exposure to air. Meat Sci. 2001;57(3):299-310.

69. Xie A, et al. Rapid detection of frozen pork quality without thawing by Vis-NIR hyperspectral imaging technique. Talanta. 2015;139:208-15.

70. Kizil, R. and J. Irudayaraj, Raman spectroscopy, In: Process analytical technology for the food industry. Springer; 2014, 103-134. https:// doi.org/10.1007/978-1-4939-0311-5_5

71. Alinovi $\mathrm{M}$, et al. Applicability of confocal raman microscopy to observe microstructural modifications of cream cheeses as influenced by freezing. Foods. 2020;9(5):679.

72. Huen J, et al. Confocal Raman microscopy of frozen bread dough. J Cereal Sci. 2014;60(3):555-60.

73. Wang $\mathrm{R}$, et al. Changes in gelation, aggregation and intermolecular forces in frozen-thawed egg yolks during freezing. Food Hydrocolloids. 2020. https://doi.org/10.1016/j.foodhyd.2020.105947.

74. Chen Q, et al. Non-destructive prediction of texture of frozen/thaw raw beef by Raman spectroscopy. J Food Eng. 2020;266:109693.

75. Hatzakis E. Nuclear magnetic resonance (NMR) spectroscopy in food science: a comprehensive review. Compr Rev Food Sci Food Saf. 2019;18(1):189-220.

76. Tan M, et al. Effect of multiple freeze-thaw cycles on the quality of instant sea cucumber: Emphatically on water status of by LF-NMR and MRI. Food Res Int. 2018;109:65-71.

77. Ali S, et al. Effect of multiple freeze-thaw cycles on the quality of chicken breast meat. Food Chem. 2015;173:808-14.

78. Lee S, Cornillon P, Kim Y. Spatial investigation of the non-frozen water distribution in frozen foods using NMR SPRITE. J Food Sci. 2002;67(6):2251-5.

79. Mahdjoub R, et al. Sucrose solution freezing studied by magnetic resonance imaging. Carbohyd Res. 2006;341(4):492-8.

80. Islam MN, et al. The effect of ultrasound-assisted immersion freezing on selected physicochemical properties of mushrooms. Int J Refrig. 2014;42:121-33.

81. Zhu Z, et al. Freezing efficiency and quality attributes as affected by voids in plant tissues during ultrasound-assisted immersion freezing. Food Bioprocess Technol. 2018;11(9):1615-26.

82. Zhang $Y$, et al. Effects of ultrasound-assisted freezing on the water migration of dough and the structural characteristics of gluten components. J Cereal Sci. 2020;94:102893.

83. Tian Y, et al. Effects of nano-bubbles and constant/variable-frequency ultrasound-assisted freezing on freezing behaviour of viscous food model systems. J Food Eng. 2021;292:110284.

84. Li B, Sun D-W. Novel methods for rapid freezing and thawing of foods-a review. Trends Food Sci. 2002;54(3):175-82.

85. Volkert $\mathrm{M}$, et al. Effects of High Pressure-Low Temperature treatment on freezing behavior, sensorial properties and air cell distribution in sugar rich dairy based frozen food foam and emulsions. Innov Food Sci Emerg Technol. 2012;13:75-85.

86. Cheng L, Zhu Z, Sun DWJ. Impacts of high pressure assisted freezing on the denaturation of polyphenol oxidase. Food Chem. 2021;335:127485.

87. Wusteman M, Robinson M, Pegg D. Vitrification of large tissues with dielectric warming: biological problems and some approaches to their solution. Cryobiology. 2004;48(2):179-89.

88. Sun, W., et al. Effect of alternated electric field on the ice formation during freezing process of 0.9\% K2MnO4 water. In: 2006 IEEE 8 th International Conference on Properties \& applications of Dielectric Materials. IEEE; 2006

89. Cheng $X$, et al. The principles of ultrasound and its application in freezing related processes of food materials: a review. Ultrason Sonochem. 2015;27:576-85.

90. Fallah-Joshaqani S, et al. Evaluation of the static electric field effects on freezing parameters of some food systems. Int J Refrig. 2019;99:30-6.

91. Wang Q, et al. Effects of ultrahigh permittivity ceramic on water freezing by high voltage electric field-assisted freezing system. Int J Refrig. 2021;128:271-80.

92. Aleksandrov V, Barannikov A, Dobritsa N. Effect of magnetic field on the supercooling of water drops. J Inorg Mater. 2000;36(9):895-8.

93. Zhan X, Zhu Z, Sun D-W. Effects of extremely low frequency electromagnetic field on the freezing processes of two liquid systems. LWT Food Sci Technol. 2019;103:212-21.

94. Tang J, Shao S, Tian C. Effects of the magnetic field on the freezing process of blueberry. Int J Refrig. 2020;113:288-95.

95. Chen A, et al. Effects of magnetic field on freezing characters of carrot, potato and broccoli. Eur Phys J Appl Phys. $2021 ; 93(1): 10201$.

96. Anese $M$, et al. Effect of radiofrequency assisted freezing on meat microstructure and quality. Food Res Int. 2012;46(1):50-4.

97. Peiró R, et al. Micronutrient flow to the osmotic solution during grapefruit osmotic dehydration. J Food Eng. 2006;74(3):299-307.

98. James C, Purnell G, James SJ. A critical review of dehydrofreezing of fruits and vegetables. Food Bioprocess Technol. 2014;7(5):1219-34.

99. Naing AH, Kim CK. A brief review of applications of antifreeze proteins in cryopreservation and metabolic genetic engineering. Biotech. 2019;9(9):329.

100. Bianco V, Espinosa JR, Vega C. Antifreeze proteins and homogeneous nucleation: on the physical determinants impeding ice crystal growth. J Chem Phys. 2020;153(9):091102.

101. Alarcon-Rojo A, et al. Power ultrasound in meat processing. Journal of Meat science. 2015;107:86-93.

102. Chandrapala J, et al. Use of power ultrasound to improve extraction and modify phase transitions in food processing. Food Rev Intl. 2013;29(1):67-91.

103. Kiani H, Sun D-W, Zhang Z. The effect of ultrasound irradiation on the convective heat transfer rate during immersion cooling of a stationary sphere. Ultrason Sonochem. 2012;19(6):1238-45.

104. Li B, Sun D-W. Effect of power ultrasound on freezing rate during immersion freezing of potatoes. J Food Eng. 2002;55(3):277-82.

105. Islam MN, et al. Direct contact ultrasound assisted freezing of mushroom (Agaricus bisporus): growth and size distribution of ice crystals. Int J Refrig. 2015;57:46-53. 
106. Delgado AE, Zheng L, Sun D-W. Influence of ultrasound on freezing rate of immersion-frozen apples. Trends Food Sci. 2009;2(3):263-70.

107. Schössler K, Jäger H, Knorr D. Novel contact ultrasound system for the accelerated freeze-drying of vegetables. Innov Food Sci Emerg Technol. 2012;16:113-20.

108. Xin Y, Zhang M, Adhikari B. The effects of ultrasound-assisted freezing on the freezing time and quality of broccoli (Brassica oleracea $L$. var. botrytis L.) during immersion freezing. Int J Refrig. 2014;41:82-91.

109. Sun $Q$, et al. The comparison of ultrasound-assisted immersion freezing, air freezing and immersion freezing on the muscle quality and physicochemical properties of common carp (Cyprinus carpio) during freezing storage. Ultrason Sonochem. 2019;51:281-91.

110. Zhu Z, Zhang P, Sun D-W. Effects of multi-frequency ultrasound on freezing rates and quality attributes of potatoes. Ultraso Sonochem. 2020;60:104733.

111. Comandini P, et al. Effects of power ultrasound on immersion freezing parameters of potatoes. Innov Food Sci Emerg Technol. 2013;18:120-5.

112. Inada T, et al. Active control of phase change from supercooled water to ice by ultrasonic vibration 1. Control of freezing temperature. Int J Heat Mass Transfer. 2001;44(23):4523-31.

113. Kiani $\mathrm{H}$, et al. Ultrasound assisted nucleation of some liquid and solid model foods during freezing. Food Res Int. 2011;44(9):2915-21.

114. Kiani $\mathrm{H}$, et al. Investigation of the effect of power ultrasound on the nucleation of water during freezing of agar gel samples in tubing vials. Ultrason Sonochem. 2012;19(3):576-81.

115. Maresca P, Ferrari G. Modeling of the microbial inactivation by high hydrostatic pressure freezing. Food Control. 2017;73:8-17.

116. Realini $C$, et al. High pressure and freezing temperature effect on quality and microbial inactivation of cured pork carpaccio. Meat Sci. 2011;88(3):542-7.

117. Hite, B.H., The effect of pressure in the preservation of milk: a preliminary report. Vol. 58. books. Google: West Virginia Agricultural Experiment Station, 1899

118. LeBail A, et al. High pressure freezing and thawing of foods: a review. Int J Refrig. 2002;25(5):504-13.

119. Knorr D, Schlueter O, Heinz V. Impact of high hydrostatic pressure on phase transitions of foods. Food Technol. 1998;52(9):42-4.

120. Kalichevsky M, Knorr D, Lillford P. Potential food applications of high-pressure effects on ice-water transitions. Trends Food Sci Technol. 1995;6(8):253-9.

121. Tironi V, De Lamballerie M, Le-Bail A. Quality changes during the frozen storage of sea bass (Dicentrarchus labrax) muscle after pressure shift freezing and pressure assisted thawing. Innov Food Sci Emerg Technol. 2010;11(4):565-73.

122. Fernández PP, et al. High-pressure shift freezing versus high-pressure assisted freezing: effects on the microstructure of a food model. Food Hydrocolloids. 2006;20(4):510-22.

123. Cheng $\mathrm{L}$, et al. Effects of high pressure freezing (HPF) on denaturation of natural actomyosin extracted from prawn (Metapenaeus ensis). Food Chem. 2017;229:252-9.

124. Chevalier D, et al. Comparison of air-blast and pressure shift freezing on Norway lobster quality. J Food Sci. 2000;65(2):329-33.

125. Teramoto A, Fuchigami M. Changes in temperature, texture, and structure of konnyaku (konjac glucomannan gel) during high-pressurefreezing. J Food Sci. 2000;65(3):491-7.

126. Martino MN, et al. Size and location of ice crystals in pork frozen by high-pressure-assisted freezing as compared to classical methods. Meat Sci. 1998;50(3):303-13.

127. Sanz P, et al. Freezing processes in high-pressure domains. Int J Refrig. 1997;20(5):301-7.

128. Choi M-J, Min S-G, Hong G-P. Effects of pressure-shift freezing conditions on the quality characteristics and histological changes of pork. LWT Food Sci Technol. 2016;67:194-9.

129. Silva JL, et al. High-pressure chemical biology and biotechnology. Chem Rev. 2014;114(14):7239-67.

130. Malinowska-Pańczyk E, et al. The effect of high pressure at subzero temperature on proteins solubility, drip loss and texture of fish (cod and salmon) and mammal's (pork and beef) meat. Food Sci Technol Int. 2014;20(5):383-95.

131. Hsu K-C, et al. Changes in conformation and in sulfhydryl groups of actomyosin of tilapia (Orechromis niloticus) on hydrostatic pressure treatment. Food Chem. 2007;103(2):560-4.

132. Rodríguez AC, et al. Electromagnetic freezing in a widespread frequency range of alternating magnetic fields. Food Eng Rev. 2019;11(2):93-103.

133. Leontyev I, Stuchebrukhov A. Electronic polarizability and the effective pair potentials of water. J Chem Theory Comput. 2010;6(10):3153-61.

134. Yu H, van Gunsteren WF. Charge-on-spring polarizable water models revisited: From water clusters to liquid water to ice. J Chem Phys. 2004;121(19):9549-64.

135. Shevkunov SV, Vegiri A. Electric field induced transitions in water clusters. J Mol Struct. 2002;593(1-3):19-32.

136. Woo MW, Mujumdar AS. Effects of electric and magnetic field on freezing and possible relevance in freeze drying. Drying Technol. 2010;28(4):433-43.

137. Petersen A, Rau G, Glasmacher B. Reduction of primary freeze-drying time by electric field induced ice nucleus formation. Heat Mass Transfer. 2006;42(10):929-38.

138. Orlowska M, Havet M, Le-Bail A. Controlled ice nucleation under high voltage DC electrostatic field conditions. Food Res Int. 2009;42(7):879-84.

139. Wei S, et al. Effects of dipole polarization of water molecules on ice formation under an electrostatic field. Cryobiology. 2008;56(1):93-9.

140. Hozumi T, et al. Effects of electrode materials on freezing of supercooled water in electric freeze control. Int J Refrig. 2003;26(5):537-42.

141. Hozumi T, et al. Effects of shapes of electrodes on freezing of supercooled water in electric freeze control. Int J Refrig. 2005;28(3):389-95.

142. Otero L, Rodríguez AC, Sanz PD. Effect of the frequency of weak oscillating magnetic fields on supercooling and freezing kinetics of pure water and 0.9\% NaCl solutions. J Food Eng. 2020;273:109822.

143. Inaba $\mathrm{H}$, et al. Effect of the magnetic field on the melting transition of $\mathrm{H} 2 \mathrm{O}$ and $\mathrm{D} 2 \mathrm{O}$ measured by a high resolution and supersensitive differential scanning calorimeter. J Appl Phys. 2004;96(11):6127-32.

144. Wowk B. Electric and magnetic fields in cryopreservation. Cryobiology. 2012;64(3):301-3. 
145. Otero L, Rodríguez AC, Sanz PD. Effect of the frequency of weak oscillating magnetic fields on supercooling and freezing kinetics of pure water and 09\% $\mathrm{NaCl}$ solutions. J Food Eng. 2020;273:109822.

146. Otero L, Rodríguez AC, Sanz PD. Effects of static magnetic fields on supercooling and freezing kinetics of pure water and $0.9 \% \mathrm{NaCl}$ solutions. J Food Eng. 2018;217:34-42.

147. Purnell G, James C, James SJ. The effects of applying oscillating magnetic fields during the freezing of apple and potato. Food Bioprocess Technol. 2017;10(12):2113-22.

148. James C, Reitz B, James SJ. The freezing characteristics of garlic bulbs (Allium sativum L.) frozen conventionally or with the assistance of an oscillating weak magnetic field. Food Bioprocess Technol. 2015;8(3):702-8.

149. Naito M, et al. Effect of a magnetic field on Drosophila under supercooled conditions. PLoS ONE. 2012;7(12):e51902.

150. Sadot $\mathrm{M}$, et al. Microwave assisted freezing part 2: Impact of microwave energy and duty cycle on ice crystal size distribution. Innov Food Sci Emerg Technol. 2020. https://doi.org/10.1016/j.ifset.2020.102359.

151. Ando $Y$, et al. Effect of air-dehydration pretreatment before freezing on the electrical impedance characteristics and texture of carrots. J Food Eng. 2016;169:114-21.

152. Liu C, et al. Effects of pulsed electric fields and preliminary vacuum drying on freezing assisted processes in potato tissue. Food Bioproducts Process. 2020. https://doi.org/10.1016/j.fbp.2020.11.002.

153. Uemura T, Tagawa A. Effect of dehydration method on the physical properties of fresh-cut radish after freezing and after post-thaw rehydration in the dehydro-freezing technique. J Jpn Soc Food Sci Technol. 2012;59(3):115-21.

154. Giannakourou MC, Dermesonlouoglou EK, Taoukis PS. Osmodehydrofreezing: an integrated process for food preservation during frozen storage. Foods. 2020;9(8):1042.

155. Ando $\mathrm{H}$, et al. The effect of osmotic dehydrofreezing on the role of the cell membrane in carrot texture softening after freeze-thawing J Food Eng. 2012;108(3):473-9.

156. Dermesonlouoglou E, Giannakourou M, Taoukis P. Kinetic modelling of the degradation of quality of osmo-dehydrofrozen tomatoes during storage. Food Chem. 2007;103(3):985-93.

157. Tregunno N, Goff H. Osmodehydrofreezing of apples: structural and textural effects. Food Res Int. 1996;29(5-6):471-9.

158. Zhao JH, et al. Effects of different osmo-dehydrofreezing treatments on the volatile compounds, phenolic compounds and physicochemical properties in mango (Mangifera indica L). Int J Food Sci Technol. 2016;51(6):1441-8.

159. Ammar JB, et al. Effect of a pulsed electric field and osmotic treatment on freezing of potato tissue. J Food Biophysics. 2010;5(3):247-54.

160. Lowithun N, Charoenrein S. Influence of osmodehydrofreezing with different sugars on the quality of frozen rambutan. Int J Food Sci Technol. 2009;44(11):2183-8.

161. Forni $E$, et al. The influence of sugar composition on the colour stability of osmodehydrofrozen intermediate moisture apricots. Food Res Int. 1997;30(2):87-94.

162. Parniakov O, et al. Effects of pulsed electric fields assisted osmotic dehydration on freezing-thawing and texture of apple tissue. J Food Eng. 2016;183:32-8.

163. Fan X, et al. Dehydrofreezing of peach: Blanching, D-sodium erythorbate vacuum infiltration, vacuum dehydration, and nitrogen packaging affect the thawed quality of peach. J Food Biochem. 2019;43(7):e12830.

164. De Maayer P, et al. Some like it cold: understanding the survival strategies of psychrophiles. EMBO Rep. 2014;15(5):508-17.

165. DeVries AL, Wohlschlag DE. Freezing resistance in some Antarctic fishes. Science. 1969;163(3871):1073-5.

166. Tomchaney A, et al. Purification, composition, and physical properties of a thermal hysteresis" antifreeze" protein from larvae of the beetle Tenebrio molitor. Biochemistry. 1982;21(4):716-21.

167. Sharma B, Sahoo D, Deswal R. Single-step purification and characterization of antifreeze proteins from leaf and berry of a freeze-tolerant shrub seabuckthorn (Hippophae rhamnoides). J Sep Sci. 2018;41(20):3938-45.

168. Newsted WJ, et al. A low molecular weight peptide from snow mold with epitopic homology to the winter flounder antifreeze protein. Biochem Cell Biol. 1994;72(3-4):152-6.

169. Wharton DA, Block W. Differential scanning calorimetry studies on an Antarctic nematode (Panagrolaimus davidi) which survives intracellular freezing. Cryobiology. 1997;34(2):114-21.

170. Cai Q, Storey KB. Upregulation of a novel gene by freezing exposure in the freeze-tolerant wood frog (Rana sylvatica). Gene. 1997;198(1-2):305-12.

171. Sun $X$, et al. Low temperature growth, freezing survival, and production of antifreeze protein by the plant growth promoting rhizobacterium Pseudomonas putida GR12-2. Can J Microbiol. 1995;41(9):776-84.

172. Raymond JA, Knight CA. Ice binding, recrystallization inhibition, and cryoprotective properties of ice-active substances associated with Antarctic sea ice diatoms. Cryobiology. 2003;46(2):174-81.

173. Xiang $\mathrm{H}$, et al. The properties, biotechnologies, and applications of antifreeze proteins. Int J Biol Macromol. 2020;153:661-75.

174. Flores $A$, et al. Mechanisms of antifreeze proteins investigated via the site-directed spin labeling technique. Eur Biophys J. 2018;47(6):611-30.

175. Scotter AJ, et al. The basis for hyperactivity of antifreeze proteins. Cryobiology. 2006;53(2):229-39.

176. Graether SP, et al. $\beta$-Helix structure and ice-binding properties of a hyperactive antifreeze protein from an insect. Nature. 2000;406(6793):325-8.

177. Hansen TN, Baust JG. Differential scanning calorimetric analysis of antifreeze protein activity in the common mealworm, Tenebrio molitor. Biochim Biophys Acta. 1988;957(2):217-21.

178. Knight C, Cheng C, DeVries A. Adsorption of alpha-helical antifreeze peptides on specific ice crystal surface planes. Biophys J. 1991;59(2):409-18.

179. Mahatabuddin S, et al. Concentration-dependent oligomerization of an alpha-helical antifreeze polypeptide makes it hyperactive. Sci Rep. 2017;7:42501.

180. Garnham CP, et al. Compound ice-binding site of an antifreeze protein revealed by mutagenesis and fluorescent tagging. Biochemistry. 2010;49(42):9063-71. 
181. Olijve LL, et al. Blocking rapid ice crystal growth through nonbasal plane adsorption of antifreeze proteins. Proc Natl Acad Sci. 2016;113(14):3740-5.

182. Payne S, et al. The effects of antifreeze proteins on chilled and frozen meat. Meat Sci. 1994;37(3):429-38.

183. Boonsupthip W, Lee TC. Application of antifreeze protein for food preservation: effect of type III antifreeze protein for preservation of gel-forming of frozen and chilled actomyosin. J Food Sci. 2003;68(5):1804-9.

184. Chen X, Wang S. Cryoprotective effect of antifreeze glycopeptide analogues obtained by nonenzymatic glycation on Streptococcus thermophilus and its possible action mechanism. Food Chem. 2019;288:239-47.

185. Kong CH, et al. Antifreeze peptide pretreatment minimizes freeze-thaw damage to cherries: An in-depth investigation. LWT Food Sci Technol. 2017;84:441-8.

186. Liu M, et al. Comparative study on the cryoprotective effects of three recombinant antifreeze proteins from Pichia pastoris GS115 on hydrated gluten proteins during freezing. J Agric Food Chem. 2018;66(24):6151-61.

187. Zhang C, et al. Improvement of texture properties and flavor of frozen dough by carrot (Daucus carota) antifreeze protein supplementation. J Agric Food Chem. 2007;55(23):9620-6.

188. Panadero J, Randez-Gil F, Prieto JA. Heterologous expression of type I antifreeze peptide GS-5 in baker's yeast increases freeze tolerance and provides enhanced gas production in frozen dough. J Agric Food Chem. 2005;53(26):9966-70.

189. Yin L-J, et al. Properties of extracellular ice-nucleating substances from Pseudomonas fluorescens MACK-4 and its effect on the freezing of some food materials. Fish Sci. 2005;71(4):941.

190. Kaleda A, et al. Ice cream structure modification by ice-binding proteins. Food Chem. 2018;246:164-71.

191. Regand A, Goff H. Ice recrystallization inhibition in ice cream as affected by ice structuring proteins from winter wheat grass. J Dairy Sci. 2006;89(1):49-57.

192. Calderara M, et al. Role of ice structuring proteins on freezing-thawing cycles of pasta sauces. J Food Sci Technol. 2016;53(12):4216-23.

193. Kong $\mathrm{CH}$, et al. Effect of antifreeze peptide pretreatment on ice crystal size, drip loss, texture, and volatile compounds of frozen carrots. J Agric Food Chem. 2016;64(21):4327-35.

194. Arai S, Watanabe M. Freeze texturing of food materials by ice-nucleation with the bacterium Erwinia ananas. Agric Biol Chem. 1986;50(1):169-75.

195. Zachariassen KE, Kristiansen E. Ice nucleation and antinucleation in nature. Cryobiology. 2000;41(4):257-79.

196. Zhang S, Wang H, Chen G. Addition of ice-nucleation active bacteria: Pseudomonas syringae pv panici on freezing of solid model food. LWT Food Sci Technol. 2010;43(9):1414-8.

197. Sun, D.-W. and L. Zheng, Innovations in freezing process, In: Handbook of frozen food processing and packaging. CRC Press; 2005, 183203. https://doi.org/10.1201/9781420027402.ch8

198. Watanabe, M. and S. Arai, Bacterial ice-nucleation activity and its application to freeze concentration of fresh foods for modification of their properties, In: Water in Foods. Elsevier; 1994, 453-473. https://doi.org/10.1016/B978-1-85861-037-5.50032-1

199. Li J, Lee TC. Bacterial extracellular ice nucleator effects on freezing of foods. J Food Sci. 1998;63(3):375-81.

200. Jin J, et al. Improved freeze drying efficiency by ice nucleation proteins with ice morphology modification. Food Res Int. 2018;106:90-7.

Publisher's Note Springer Nature remains neutral with regard to jurisdictional claims in published maps and institutional affiliations. 